\title{
An effective regional Marine Protected Area network for the ROPME Sea Area: Unrealistic vision or realistic possibility?
}

\author{
Hanneke Van Lavieren ${ }^{\mathrm{a}, *}$, Rebecca Klaus ${ }^{\mathrm{b}}$ \\ ${ }^{a}$ United Nations University, Institute for Water, Environment \&' Health (UNU-INWEH), 175 Longwood Road South, Hamilton, Ontario, Canada L8P OA1 \\ ${ }^{\mathrm{b}}$ Tropical Marine Ecosystems of the Future, LOEWE Biodiversity and Climate Research Centre (BiK-F), Senckenberg Research Institute and Nature Museum Frankfurt, Marine \\ Zoology/Ichthyology, Senckenberganlage 25, D-60325 Frankfurt a.M., Germany
}

\section{A R T I C L E I N F O}

\section{Keywords:}

Management effectiveness

Marine Protected Areas (MPA)

Regional MPA network

ROPME Sea Area

\begin{abstract}
A B S T R A C T
Convention on Biodiversity (CBD) targets aim to encourage the establishment of an effective global network of MPAs covering $10 \%$ of coastal and marine ecoregions by 2020 . This paper presents findings from the first ever regional assessment of MPA management effectiveness in the ROPME (Regional Organisation for the Protection of the Marine Environment) Sea Area (RSA). The RSA, extends from the Gulf to the Arabian Sea coast of Oman, and is bordered by 8 member states, including some of the world's richest and fastest growing global economies. There are 173 MPAs covering $7.8 \%$ of the RSA (36,182.03 $\left.\mathrm{km}^{2}\right)$. Progress towards CBD MPA targets is lower as: (i) stated area coverages often include a terrestrial component; (ii) only $37 \%$ are legally 'Designated' (5.4\% RSA), while $73 \%$ remain 'Proposed' (2.4\% RSA) and; (iii) assessment of management effectiveness revealed variable levels of performance ( $11 \%$ to $58 \%$, with an average of 34\%). Underlying causes for low performance are discussed and recommendations are offered to help RSA member states meet CBD MPA targets by 2020.
\end{abstract}

(C) 2012 Elsevier Ltd. All rights reserved.

\section{Introduction}

Given the increasingly degraded state of the global marine environment (Rogers and Laffoley, 2011), Marine Protected Areas (MPAs), including fisheries 'No-take' zones, together with other management approaches such as Integrated Coastal Zone Management (ICZM) are now recognised as essential tools to help reduce, prevent and/or reverse ongoing declines in marine biodiversity, habitats and fisheries productivity (Murray et al., 1999; Pauly et al., 2002; Gell and Roberts, 2003; Roberts et al., 2005; Laffoley, 2008). MPAs can help support and improve ecosystem function (Agardy, 2000) through maintaining or re-establishing ecological structure, function and processes that support economic and social uses and values across the world (Laffoley, 2008). MPAs also have a vital role to play in mitigating the effects of climate variability and change (Dudley et al., 2010; Mackinnon et al., 2011) and can contribute towards climate change adaptation by protecting ecosystem resilience, buffering local climate impacts, reducing the risks and impacts of extreme events (e.g. storm waves, coastal flooding, sea level rise), and protecting essential ecosystem services (Dudley et al., 2010).

Networks or systems of MPAs are now widely recognised as a means of building resilience and supporting recovery in response

\footnotetext{
* Corresponding author. Tel.: +1 905667 5494; fax: +1 9056675510.

E-mail address: Hanneke.VanLavieren@unu.edu (H. Van Lavieren).
}

to extreme 'pulse' impacts (McLeod and Salm, 2006; Spalding et al., 2008). MPA networks account for the transboundary nature of marine environments, and the connections between associated habitats and ecosystems. A comprehensive, adequate and representative MPA network can provide protection for all major ecosystem components in conjunction with characteristic habitats and species at appropriate scales within and across regions.

The importance of establishing networks of MPAs was first recognised by the international community in 2002, when the first international MPA target was set to establish a global network of MPAs by 2012 (WSSD, 2002). In 2004, signatories of the Convention on Biological Diversity (CBD) agreed to establish "a global network of comprehensive, representative and effectively managed national and regional protected area systems" of terrestrial protected areas by 2010 and MPAs by 2012. The following CBD Conference of the Parties (COPs) in 2005, decided to establish goals, sub-targets and indicators for each of the focal areas, to adopt a new programme of work on protected areas (POWPAs), and a revised programme of work on marine and coastal biodiversity. In 2006, at COP 8 the target was quantified to state that there should be effective conservation of at least $10 \%$ of each of the world's ecological regions by 2012 (CBD, 2006). There were various discussions about which organisations would be most suitable for helping to organise and coordinate these efforts, and the value of using the UNEP Regional Seas Programme (RSP) was recognised, even though there were certain capacity concerns (IUCN-WCPA, 
2008). In 2010, governments adopted the so called 'Aichi targets' in Nagoya, which set a new target for at least $17 \%$ of terrestrial areas to be protected and $10 \%$ of the oceans to be designated within MPAs by 2020 (CBD, 2010).

Despite these global agreements, progress is falling well behind what is needed to meet these targets and secure improved conservation of our oceans and seas (Laffoley, 2008). Global MPA coverage is still vastly under represented as compared to the achievements within the terrestrial realm. In 2003, only $0.45 \%$ of the global ocean surface area or $1.14 \%$ of Exclusive Economic Zones (EEZs), was protected within 4116 MPAs (Chape et al., 2003). By 2006, there were 4435 MPAs protecting 2.35 million $\mathrm{km}^{2}$, equivalent to $0.65 \%$ of the global oceans or $1.63 \%$ of EEZs (Wood et al., 2008), which compared poorly to achievements in the terrestrial domain, where 104,791 protected areas covered 18.38 million $\mathrm{km}^{2}$, equivalent to $12 \%$ of the global land surface area (Chape et al., 2005). By 2008, there were 5045 MPAs, protecting a total of 2.59 million $\mathrm{km}^{2}$, equivalent to $0.72 \%$ of the global oceans or $1.80 \%$ of EEZs (Spalding et al., 2008). Global MPA coverage has now reached 4.21 million $\mathrm{km}^{2}$, with 5850 MPAs covering $1.17 \%$ of the global ocean surface or $2.86 \%$ of the EEZs (Spalding et al., 2010 ). While the $1.17 \%$ coverage represents a $150 \%$ increase in the last decade, the under-representation of MPAs is alarming, especially considering that oceans cover $70 \%$ of the earth's surface and $95 \%$ of the volume of habitable areas on earth (Laffoley, 2008). The global distribution of MPAs is both uneven and unrepresentative at multiple scales, and only half of the world's MPAs could be considered to be part of a coherent network (Wood et al., 2008; Spalding et al., 2010).

A number of studies have identified different sets of criteria to aid the design of effective MPA networks (e.g., Roberts et al., 2003a, 2003b; UNEP-WCMC, 2008; IUCN-WCPA, 2008), whether at the national or regional scale, which can be broadly summarised as: (1) Effectiveness (i.e. individual MPAs need to be meeting their management objectives and addressing threats in order for the network to work as a whole); (2) Representativeness (i.e. MPAs should cover a representative and heterogeneous proportion of all biodiversity typologies, from genetic diversity to habitats, as well as physical structures, from landscapes to habitats, and functional ecological and evolutionary processes, all of which are characteristic of the bio-geographical region); (3) Connectivity (i.e. MPA networks should recognise the patterns of connectivity within and among habitats, to ensure the exchange of larvae and propagules can be sustained and the replenishment of affected populations); (4) Replication (i.e. the features mentioned above, should be replicated within the network, as this provides contingency in the event of a serious impact, and increases the level of connectivity); (5) Resilience (i.e. which can be achieved through protecting areas with the capacity to survive natural catastrophes or disasters, together with replication and redundancy); (6) Adequacy (i.e. within an MPA network there is a need to ensure that the size and shape of individual MPAs are sufficient to be able to maintain ecologically viable populations) and; (7) Governance Frameworks (i.e. legal structures, and monitoring control and surveillance, broader management regimes including ICZM and, stakeholder and community participation in decision making and management).

Worldwide, the ability to assess the status and effectiveness of individual MPAs, as well as to monitor progress towards the CBD targets has been constrained by the lack of robust data (Wood et al., 2008). A first analysis of progress towards achieving national and regional MPA networks found that most MPA are established on an ad hoc basis without systematic planning processes and that most national MPA networks comprise of a wide range of different MPA management and governance types, without adequate monitoring programs to measure progress in towards international targets (UNEP-WCMC, 2008). One of the regions where information on progress towards the CBD MPA targets is low is the Regional Organisation for the Protection of the Marine Environment (ROPME) Sea Area (RSA) (Fig. 1).

\subsection{Regional Organisation for the Protection of the Marine Environment (ROPME) Sea Area (RSA)}

The ROPME Sea Area (RSA) includes the Persian or Arabian Gulf (hereafter referred to as the Gulf), the Gulf of Oman and the south eastern coasts of Oman located in the Arabian Sea. The RSA is bordered by eight countries including the Islamic Republic of Iran, Republic of Iraq, State of Kuwait, Kingdom of Saudi Arabia, Kingdom of Bahrain, State of Qatar, the United Arab Emirates, and Sultanate of Oman all of whom are member Nation States of ROPME (hereafter referred to as ROPME countries). The southern boundary of the RSA, extends from the south-west coast of Oman, eastwards through the Arabian Sea and across the Gulf of Oman to the Iranian coast. This boundary is legally defined by Article II of the Kuwait Regional Convention $\left(16^{\circ} 39^{\prime} \mathrm{N}, 53^{\circ} 3^{\prime} 30^{\prime \prime} \mathrm{E} ; 16^{\circ} 00^{\prime} \mathrm{N}, 53^{\circ} 25^{\prime} \mathrm{E}\right.$; $\left.17^{\circ} 00^{\prime} \mathrm{N}, 56^{\circ} 30^{\prime} \mathrm{E} ; 20^{\circ} 30^{\prime} \mathrm{N}, 60^{\circ} 00^{\prime} \mathrm{E} ; 25^{\circ} 04^{\prime} \mathrm{N}, 61^{\circ} 25^{\prime} \mathrm{E}\right)$. The extreme oceanographic and meteorological characteristics of this region has created a unique marine environment with ecosystems that may be resilient to some stressors, but are low in species diversity and particularly sensitive to certain anthropogenic impacts, especially in the context of likely climate change impacts (IPCC, 2007). The unique nature of marine ecosystems of the Gulf and the wider RSA have been well described (Riegl, 1998; Wilson et al., 2002; Riegl et al., 2006, 2012; Sheppard et al., 2010; Burt et al., 2011) but not as well appreciated. For example, 70\% of original reef cover in the Gulf may be considered lost and a further 27\% threatened or at critical stages of degradation (Wilkinson, 2008).

The RSA has seen remarkable economic and social development in recent years and contains some of the richest and fastest growing economies in the world (Table 1; World Bank, 2012; UN DESA, 2010). By the early 1990s some of the Gulf countries had already developed more than $40 \%$ of their coastlines (Price et al., 1993; ROPME, 2003). Rapid coastal development continues to pose a major threat to the marine ecosystems as urban populations along the Gulf's shores continue to grow (Khan, 2007; Sheppard et al., 2010; Van Lavieren et al., 2011). The total population of countries in this region is estimated to grow from approximately 149 million in 2010 to 164 million by 2015 (CIESIN, 2005), which represents an annual growth rate of $2.1 \%$, nearly double the world average of $1.1 \%$. Existing levels of development have already altered natural coastal hydrodynamics and led to the loss and degradation of important marine habitats (Burt et al., 2008; Sheppard et al., 2010; Sale et al., 2011). The continued cumulative impacts of industrial, infrastructure-based, and residential and tourism development activities, combined with climate change impacts, will synergistically amplify the observed marked decline in the status of marine ecosystem health (Sheppard et al., 2010; Sale et al., 2011).

\subsection{Marine and coastal management in the RSA}

ROPME was established in 1979 and acts as the Secretariat for the Kuwait Convention for the Protection and Development of the Marine Environment and Coastal Areas, the basic legal instrument binding each member state to coordinate activities towards the protection of their common marine environment. Member States are also party to a significant number of other regional and international agreements concerning the protection of coastal environments and biodiversity, and each country has national legislation provide guiding principles for environmental protection and conservation. While there is room for more legislation, it is 


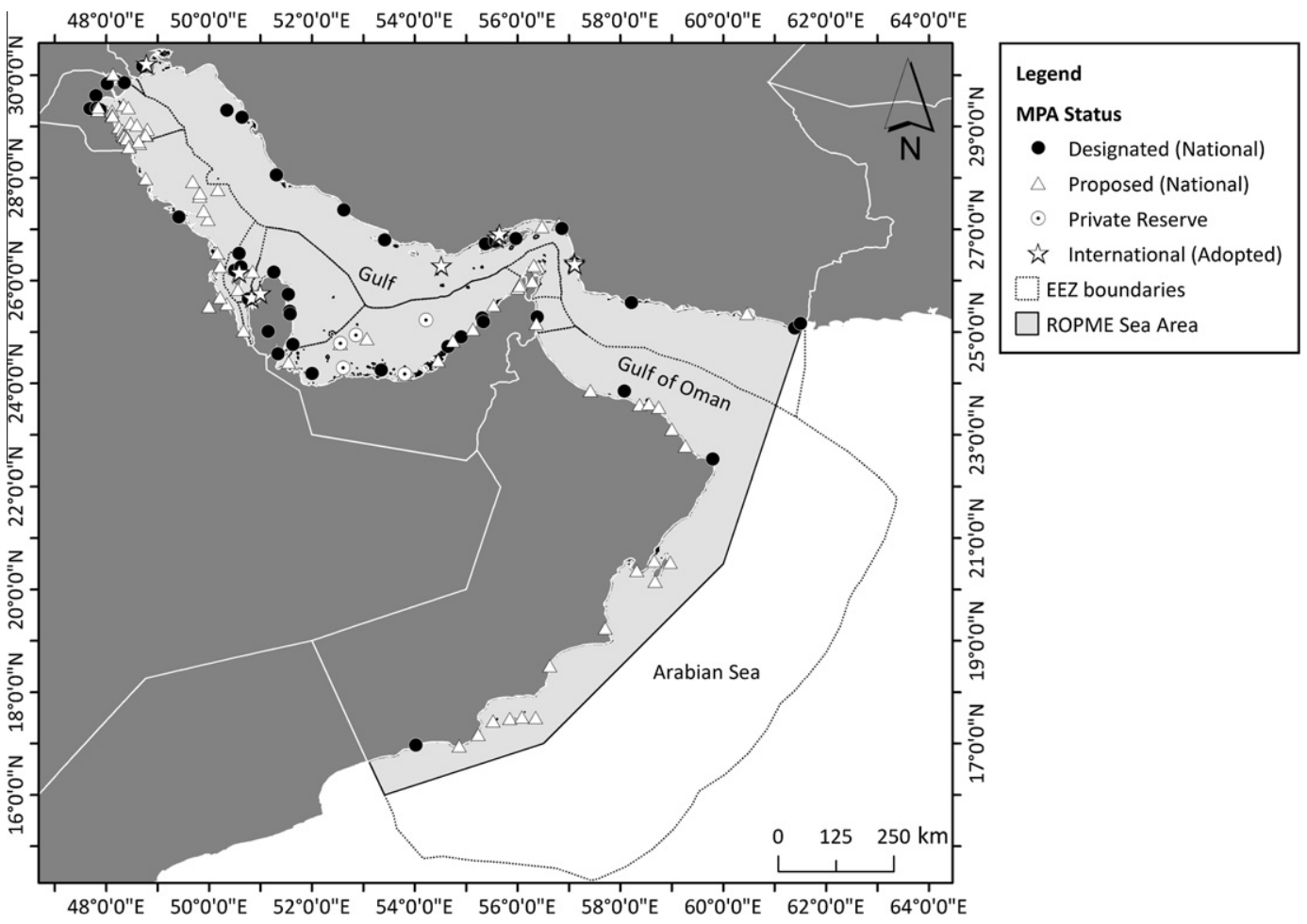

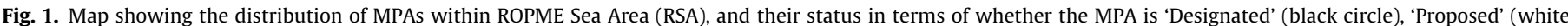

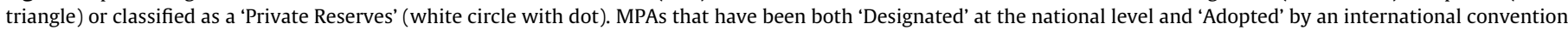

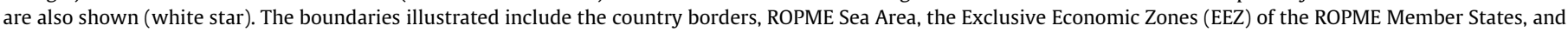

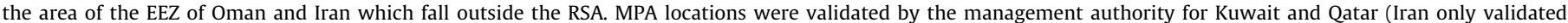

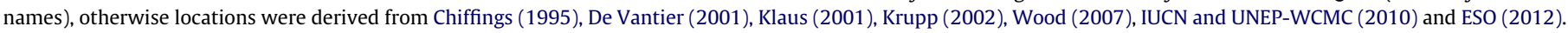

Table 1

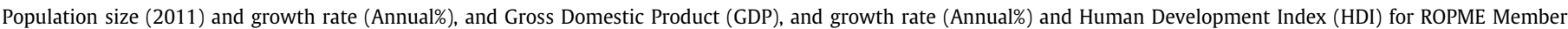
States.

\begin{tabular}{|c|c|c|c|c|c|c|c|c|c|}
\hline \multirow[t]{2}{*}{ Country } & \multirow[t]{2}{*}{ Population $(2011)^{a}$} & \multicolumn{3}{|c|}{ Population growth rate (Annual\%) ${ }^{a}$} & \multirow{2}{*}{$\begin{array}{l}\text { GDP (million US\$) } \\
(2011)^{\mathrm{a}}\end{array}$} & \multicolumn{3}{|c|}{ GDP growth (Annual\%) ${ }^{\mathrm{a}}$} & \multirow[t]{2}{*}{ HDI $(2011)^{b}$} \\
\hline & & 2009 & 2010 & 2011 & & 2009 & 2010 & 2011 & \\
\hline Bahrain & $1,323,535$ & 10.6 & 7.6 & 4.8 & $22,945^{c}$ & 3.1 & 4.5 & & 0.806 \\
\hline Iran & $74,798,599$ & 1.2 & 1.1 & 1.1 & $331,015^{d}$ & 1.8 & & & 0.707 \\
\hline Kuwait & $2,818,042$ & 3.8 & 3.4 & 2.9 & 176,590 & -5.2 & 3.4 & 8.2 & 0.760 \\
\hline Oman & $2,846,145$ & 2.8 & 2.6 & 2.3 & 71,781 & 1.1 & 4.0 & 5.5 & 0.705 \\
\hline Qatar & $1,870,041$ & 13.5 & 9.6 & 6.1 & 172,981 & 12.0 & 16.6 & 18.8 & 0.831 \\
\hline Saudi Arabia & $28,082,541$ & 2.4 & 2.4 & 2.3 & 576,824 & 0.1 & 4.6 & 6.8 & 0.77 \\
\hline UAE & $7,890,924$ & 11.2 & 7.9 & 4.9 & 360,245 & -1.6 & 1.4 & 4.9 & 0.846 \\
\hline
\end{tabular}

a World Bank (2012).

b http://hdr.undp.org/en/data/profiles/.

c 2010.

d 2009.

mostly implementation and enforcement of current agreements that requires strengthening (UNEP, 1999; Khan, 2007).

Recommendations for the establishment of an integrated network of MPAs within the RSA, covering a representative proportion of the regions biological and geological diversity and including prime examples of each major habitat, ecosystem and species community type was first proposed by Krupp et al. (1996). Over the past decade there has been a flourish of attention given to coastal management issues in this region, and several calls have been made for a more regional and holistic approach to coastal management in the RSA (Hamza, 2000; Munawar et al., 2002; Krupp, 2002; Khan, 2007; Sheppard et al., 2010; Sale et al., 2011; Van Lavieren et al., 2011). A review of the MPA coverage in the Gulf (Krupp, 2002) identified that proposed and established marine reserves collectively covered an area of about $13,000 \mathrm{~km}^{2}$ (including the terrestrial parts of MPAs), which is equivalent to $5 \%$ of the Gulf's surface area. Established MPAs covered as little as $7500 \mathrm{~km}^{2}$, equivalent to $3 \%$ of the total area, and just over $1 \%$ of the sea surface area. A more recent review of the MPAs in the Gulf (Al-Cibahy et al., 2012) revealed that $7.23 \%$ of the Gulf has been 'Proposed' or 'Designated' as MPAs. Although these figures do not meet the $10 \%$ target, they appear promising in comparison with global statistics, which indicate that close to $75 \%$ of 190 coastal states and territories have less than $1 \%$ of their EEZ (or equivalent) within MPAs, and $63 \%$ have less than $0.5 \%$ protected (Spalding et al., 2010). The number and coverage of MPAs does not however provide an indication of whether or not these MPAs are actually being managed and whether management is effective (Chape et al., 2005).

\subsection{Methods for assessing protected area management effectiveness}

Since the early 1990s a variety of different tools have been developed to assess and evaluate protected area management effectiveness (often known as PAME) (Rivero Blanco and Gabaldon, 
1992; Cifuentes et al., 2000; Hockings et al., 2000; Hockings, 2003; Stolton et al., 2003, 2007; Staub and Hatziolos, 2004; Leverington et al., 2010). Over the past decade, many countries have begun to apply PAME methodologies to assess the effectiveness of their MPAs and networks and funding agencies now often require such evaluations for all project interventions that involve protected areas (Belokurov et al., 2009). An increasingly large body of experience has also been developed on how to put in place effective MPAs and meaningful MPA networks (McLeod et al., 2008; Laffoley, 2008).

The methods for evaluating effectiveness can be broadly divided into three different categories, each requiring different amounts of data collection and financial input (Hockings et al., 2000). These range from the simplest (Level 1) questionnaire based methods to more complex (Level 3) full management effectiveness evaluations. Full management effectiveness evaluations often involve the collection of additional field data, they are time consuming and require considerable financial commitment (Leverington et al., 2010). The questionnaire or scorecard based methods (Stolton et al., 2003, 2007; Staub and Hatziolos, 2004) rely entirely upon available information, from the literature and from informed opinions of site managers and/or independent assessors. This method takes a short time to complete and costs little. While the potential depth of analysis is generally lower than is achievable with the more in-depth methods most issues are broadly covered.

An MPA Scorecard was developed by Staub and Hatziolos (2004) specifically for evaluating the effectiveness of MPAs. The MPA Scorecared was adapted from the World Bank/World Wildlife Fund (WWF) Alliance method for assessing the management effectiveness of terrestrial protected areas (Stolton et al., 2003), alongside other tools (Hockings et al., 2000; Mangubhai, 2003). The terrestrial scorecard has since been updated and re-branded as the World Bank/WWF Management Effectiveness Tracking Tool (METT) (Stolton et al., 2007). The World Bank, WWF and Global Environment Facility (GEF) have now adopted these methods in their monitoring and evaluation of project progress. Most GEF funded projects now require that assessments be completed three times during a project cycle. The version developed for the marine environment by Staub and Hatziolos (2004), is nearly identical to the METT and, as it was developed specifically, it remains the most appropriate of these global tools for assessing MPAs.

This paper presents the findings of the first attempt to assess the management effectiveness of MPAs in the RSA using the MPA Scorecard (Staub and Hatziolos, 2004). Application of this method provides an up to date overview of the current (designated and proposed) number and extent of MPAs, and aims to provide a picture of their status, factors influencing management effectiveness and changes needed to improve management strategies and approaches. It also attempts to assess progress achieved towards the MPA targets set by the CBD.

\section{Methods}

\subsection{MPA coverage and status}

A comprehensive list of all the MPAs within the RSA was compiled from a review of the literature (Chiffings, 1995; De Vantier, 2001; Klaus, 2001; Krupp, 2002; Van Lavieren et al., 2011). The list was cross-validated against those included in the current version of the World Database on Protected Areas (WDPA) (IUCN and UNEP-WCMC, 2010) and MPA global database (Wood, 2007), and a final consolidated list of all MPAs within the RSA was prepared. The MPAs included in the list were those that had either been identified as MPAs in the literature or in the WDPA and followed the International Union for the Conservation of Nature's (IUCN) defini- tion of an MPA: "Any area of intertidal or sub-tidal terrain, together with its overlying water and associated flora, fauna, historical and cultural features, which has been reserved by law or other effective means to protect part or all of the enclosed environment" (Kelleher, 1999). Although many of the MPAs in the RSA contain a significant terrestrial component (e.g. UNESCO Man and Biosphere Reserves) these were still included in the list. The final list of MPAs was sent out to the relevant contact within the mandated management authority in each country for validation purposes. Iraq was the only country not included in the survey as there are currently no MPAs in Iraq. Management authority representatives were asked to review the list of MPAs for their country and to update the information where necessary (MPA name, IUCN category (Laffoley, 2008), Date, Latitude and Longitude, Designation, Status, Area, Lead management authority). The geographical area included in this survey (shown in Fig. 1) is that of the RSA $\left(466,877.4 \mathrm{~km}^{2}\right)$, composed of the Inner ROPME Sea Area (RSA), covering the whole of the Gulf $\left(239,600 \mathrm{~km}^{2}\right)$ and the Outer RSA, covering the part of the Gulf of Oman (to the eastern border of Iran) and the Arabian Sea coast of Oman $\left(227,277 \mathrm{~km}^{2}\right)$.

\subsection{MPA Scorecard}

The MPA Scorecard (Staub and Hatziolos, 2004) is a simple questionnaire that is specifically designed as a quick mechanism to assess the current status of MPAs and for monitoring progress towards achieving effective management over time. The questionnaire requires no primary field data collection, instead, it relies upon the use of existing knowledge either from the literature or from the expert opinion of site managers and/or independent organisations (e.g., NGOs, dive operators) or other appropriately qualified individuals (e.g., academics, local scientists, or experts).

The MPA Scorecard (Staub and Hatziolos, 2004) has two main parts: (1) A Data Sheet to gather information about the characteristics of the MPA (e.g. geographical location, size, status, mandated management authority) and the objectives of the MPA and (2) the Assessment Sheet, which comprises 34 main questions under six main headings (Context, Planning, Inputs, Processes, Output and Outcomes) and supplementary questions which, if answered, can accrue additional points. The main headings used in the MPA Scorecard reflect the main stages in IUCN-World Commission on Protected Areas (WCPA) Management Framework, which assumes that best practice protected area management has six distinct elements or stages: it begins with (A) understanding the context of existing values and threats, progresses through (B) planning, and (C) allocation of resources (inputs), and (D) as a result of management actions (processes), eventually (E) produces products and services (outputs), that result in (F) impacts or outcomes. The grouping of questions under these six main headings thus allows for the results to be assessed for each stage in the process, according to the six main elements in the IUCN-WCPA Framework.

The MPA Scorecard Datasheet and Assessment Sheet were transferred into a standard Excel spreadsheet format and distributed (along with a set of instructions on how to complete the assessment) to two sets of potential assessors: (i) relevant contact points within the mandated management authority and (ii) other independent local experts outside of the management authority. A range of government representatives, managers, and scientists/ professionals familiar with the MPAs in the RSA were invited to participate in this survey. All assessors were asked to complete both the Data Sheet and the Assessment Sheet. The management authority representatives were also asked to complete the MPA Scorecard for as many MPAs as possible (Proposed and Designated). The local experts outside of the management authority were asked to complete the MPA Scorecard for those MPAs with which they were most familiar. 
The main questions in the MPA Scorecard are answered using a ranking scheme of between 0 (low) and 3 (high) which reflects the level of performance. A series of fixed multiple-choice answers ranked $0-3$ is provided for each question to help standardise the ranking. If none of the four alternative ranked answers exactly fit with the conditions in the MPA, assessors were instructed to select the nearest appropriate answer and to use the comments box to add qualitative statements to justify the ranking (e.g. personal opinion, a reference document, monitoring results or other studies and assessments). Assessors were also asked to indicate if the question was not relevant (NR) or if they did not know the answer to the question (DK). These questions were omitted with a reason given in the comments section.

\subsection{Analysis of data}

Results from the MPA list were used to create a final list of MPAs for the region. The MPA list was also cross-validated against the results from the Datasheets from the MPA Scorecards. The MPA Scorecards from each country were compiled and analysed at the national and regional level. The results presented here focus on the regional analysis as only one country successfully completed the MPA Scorecards for all MPAs, whether 'Designated' or 'Proposed'. As a consequence of this, and to avoid biasing the results, only those MPAs that were either privately owned, 'Designated' or had commenced the legal process of gazetting, were included in the regional analysis. The performance scores for each individual questions were analysed and summarised according to the six main stages (Context, Planning, Inputs, Processes, Output and Outcomes) in the IUCN-WCPA Framework. The results from the six main stages were used to calculate an Overall Score for management effectiveness.

\section{Results}

\subsection{Numbers, extent and status of MPAs in the RSA region}

Compilation of the MPAs lists revealed numerous discrepancies (names, status, and area coverage of MPAs) between the WDPA and the national and regional references (e.g., Krupp, 2002; IUCN and UNEP-WCMC, 2010; Al-Cibahy et al., 2012). The name and status issues were resolved for Iran, Kuwait, and Qatar by the relevant authorities who validated the MPA lists. The area coverage issues were resolved for Kuwait and Qatar who completed MPA Scorecards and declared the relative percentage of marine versus terrestrial area coverage within their MPAs. For the other countries the information used is based on Krupp (2002), cross referenced with the WDPA and Al-Cibahy et al. (2012) for more recent MPAs. The total area coverage stated for many of the MPAs in this region incorporates both marine and terrestrial areas, and it was often not possible to distinguish the relative contribution of these from either the literature or the WDPA. The area coverage estimates are thus most likely an overestimation of the actual marine area protected. This is however a global problem that is not restricted to this region.

The distribution of MPAs (Fig. 1), number of MPAs (Table 2) and protected area coverage (Table 3 ) varies considerably between countries within the RSA. The number (and area) of MPAs has grown steadily over the past few decades (Fig. 2). Iraq has a relatively small coastline and is the only country which does not yet have a single officially designated MPA. The survey identified 173 MPAs within the RSA, which includes 64 officially 'Designated' MPAs covering an estimated $24,993.33 \mathrm{~km}^{2}$ in the Gulf and Gulf of Oman and a further 109 'Proposed' national MPAs, which would cover and additional $11,188.70 \mathrm{~km}^{2}$ were they to be legally declared (Table 2, Table 3 and Fig. 1). Of these, 7 MPAs have been 'Adopted' as RAMSAR sites, two have been 'Adopted' and 3 'Proposed' as UNESCO-MAB, and five sites have been proposed for consideration as World Heritage sites (Table 2).

National coverage by existing MPAs ('Designated') ranged from $0 \%$ (Iraq) to $12.73 \%$ (UAE) of the EEZs, with an average national coverage of $5.38 \%$ of the EEZs protected for the countries in the RSA. Were all MPAs to be implemented ('Designated' and 'Proposed') this figure would increase to $8.1 \%$ of the EEZs protected. Considering the national MPA coverage as a percentage of the territorial waters of each country revealed that existing MPA ('Designated') coverage ranges from $0 \%$ (Iraq) to $22.4 \%$ (UAE), with an average national coverage of $10.75 \%$ of the territorial waters for the countries in the RSA. Were all MPAs to be implemented, four countries would exceed the $10 \%$ target (Bahrain, Iran, Kuwait, and UAE), and the average coverage would increase to $16.25 \%$ as a percentage of territorial waters. These figures are (as metioned above) likely to be an over-estimate given that they include a terrestrial proportion for most countries (with the exception of Kuwait).

\subsection{Summary of current number, area, status and governance of MPAs per country}

\subsubsection{Kingdom of Bahrain (BHR)}

The MPA list was not validated by the Public Commission for the Protection of Marine Resources, Environment and Wildlife, and no scorecards were completed within the timeframe for this paper; hence the information presented here is based on available literature. There are currently 5 MPAs in Bahrain (Hawar Islands, Ras Sanad (Tubli Bay), Fasht Bulthama, Duwhat Arad, and Mashtan) covering an area of $597 \mathrm{~km}^{2}$, which is $14.9 \%$ of territorial waters

Table 2

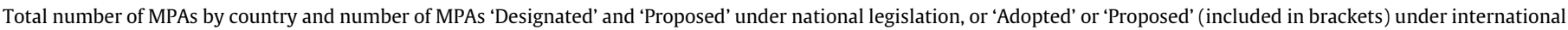
conventions (Wetland of International Importance (RAMSAR), UNESCO Man and Biosphere Reserve or World Heritage Site).

\begin{tabular}{|c|c|c|c|c|c|c|}
\hline Country & Total number of MPAs & Designated & Proposed & RAMSAR & UNESCO-MAB & World Heritage Site (proposed) \\
\hline Bahrain $^{\mathrm{b}}$ & 7 & 5 & 2 & 2 & [1] & [1] \\
\hline $\operatorname{Iran}^{\mathrm{a}}$ & 31 & 17 & 14 & 5 & [1] & {$[2]$} \\
\hline Iraq & 0 & 0 & 0 & 0 & 0 & 0 \\
\hline Kuwait $^{\mathrm{a}}$ & 30 & 6 & 24 & 0 & 0 & 0 \\
\hline Oman $^{\mathrm{b}}$ & 54 & 13 & 41 & 0 & 0 & 0 \\
\hline Qatar $^{\mathrm{a}}$ & 7 & 7 & 0 & 0 & 1 & [1] \\
\hline Saudi Arabiab & 16 & 1 & 15 & 0 & 0 & 0 \\
\hline United Arab Emirates ${ }^{b}$ & 28 & 15 & 13 & 0 & $1[1]$ & {$[1]$} \\
\hline Total & 173 & 64 & 109 & 7 & 2 & 0 \\
\hline
\end{tabular}

a MPA list validated by the management authority.

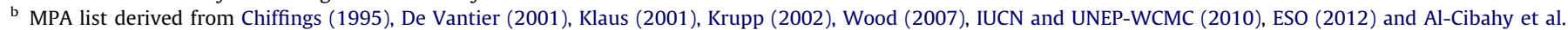
(2012). 


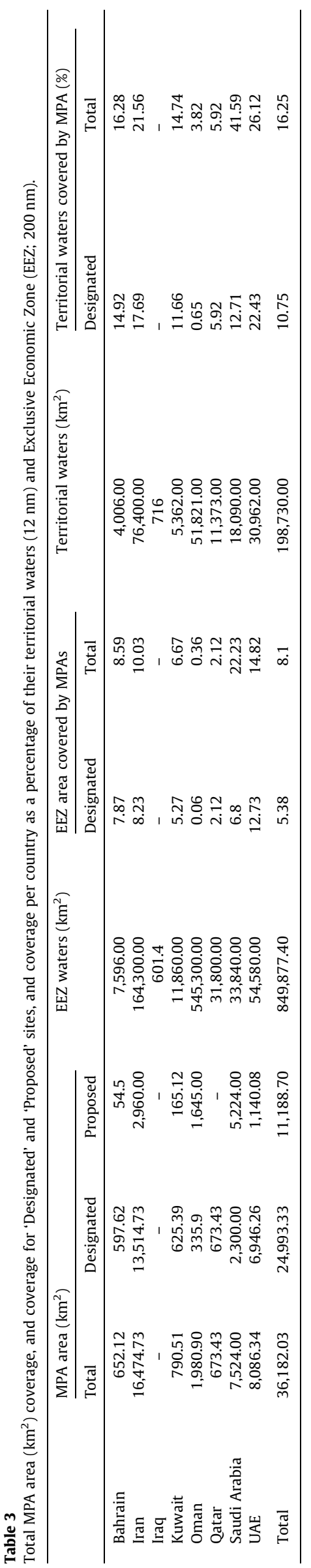

and $7.9 \%$ of the EEZ (Table 3 and Fig. 1). An additional two MPAs are 'Proposed' (Askar Coastal Area and Fasht al-Adhm).

\subsubsection{Republic of Iran}

The MPA list was validated by the Iranian Department of the Environment (DOE), the national authority responsible for MPAs. Only one scorecard was completed within the timeframe for this paper, hence the majority of the information included here is based on available literature. With the longest coastline in the Gulf, there are currently 17 MPAs in Iran covering an area of $13,514.73 \mathrm{~km}^{2}$ which is $17.7 \%$ of the territorial waters and $8.2 \%$ of the EEZ (Table 3 and Fig. 1). An additional 14 MPAs have been 'Proposed'. The Iranian Protected Areas Network (PAN) is the main tool for conserving and protecting biodiversity and nature in Iran.

\subsubsection{The State of Kuwait}

The MPA list was validated by the Environment Public Authority (EPA) of Kuwait, and 30 MPA scorecards were completed. There are currently 6 MPAs in Kuwait covering an area of $625.4 \mathrm{~km}^{2}$ which is $11.7 \%$ of their territorial waters and $5.3 \%$ of the EEZ (Table 3 and Fig. 1). An additional 24 MPAs have been 'Proposed'. MPAs are established by Amiri Decrees. The Doha Nature Reserve, established in 1988, is located on the south side of Kuwait Bay. The first three nautical miles off the coast of Kuwait are protected from fishing. Currently a small MPA is being planned $\left(1.4 \mathrm{~km}^{2}\right)$ in Sulaibikhat Bay (a subsystem of Kuwait Bay) with the purpose of compensating loss of ecosystem services during the war with Iraq (1990), however this area remains to be officially 'Designated' (pers. comm., James Bishop). Kuwait's MPAs are under the direct supervision of the EPA and the Public Authority for Agriculture and Fish Resources (PAAFR). Kuwait University (KU) and Kuwait Institute for Scientific Research (KISR) are also involved in conservation and research on MPAs in Kuwait. To date there are no internationally recognised MPAs in Kuwait.

\subsubsection{Sultanate of Oman}

The MPA list was not validated by the Directorate General of Environmental Affairs (DGEA), the management authority responsible for MPAs in Oman, within the timeframe for this paper. Only one MPA Scorecard was completed, hence the majority of the information included here is based on a literature review. There are currently 13 MPAs in Oman covering an area of $336 \mathrm{~km}^{2}$ (figure excludes Jebel Samhan, as only a small unknown proportion of this MPA is coastal/marine) which is $0.65 \%$ of the territorial waters and $0.06 \%$ of the EEZ (Table 3 and Fig. 1). An additional 41 sites have been 'Proposed' (Chiffings, 1995; De Vantier, 2001) but the current status of these is unknown. Oman has one fully marine MPA in the Gulf of Oman (Ad-Dimniyat Islands) and the Turtle Reserve on the border with the Arabian Sea (which combines the Ras Al Haad National Scenic Reserve with Ras Al Jinz National Nature Reserve) (ESO, 2012). The majority of other 'Designated' and 'Proposed' sites are the Khawrs along the Dohfar and Salalah coast. The Mussandam Peninsula is considered as an important diving destination for its spectacular coral reef areas and there are a several proposed sites around the peninsular.

\subsubsection{The Kingdom of Saudi Arabia (KSA)}

The MPA list was not validated by the national authority in Saudi Arabia within the timeframe for this paper, and only one MPA Scorecard was completed, hence the majority of the information included here is based mainly on the literature review. There is only one 'Designated' MPA (Jubail Marine Wildlife Sanctuary) in KSA covering an area of $2300 \mathrm{~km}^{2}$ which is $12.7 \%$ of their territorial waters (in the Gulf excluding the Red Sea) and 6.8\% of the EEZ (Table 3 and Fig. 1). There are a further 15 proposed sites but the current status of these is unknown. A further 11 environmentally 


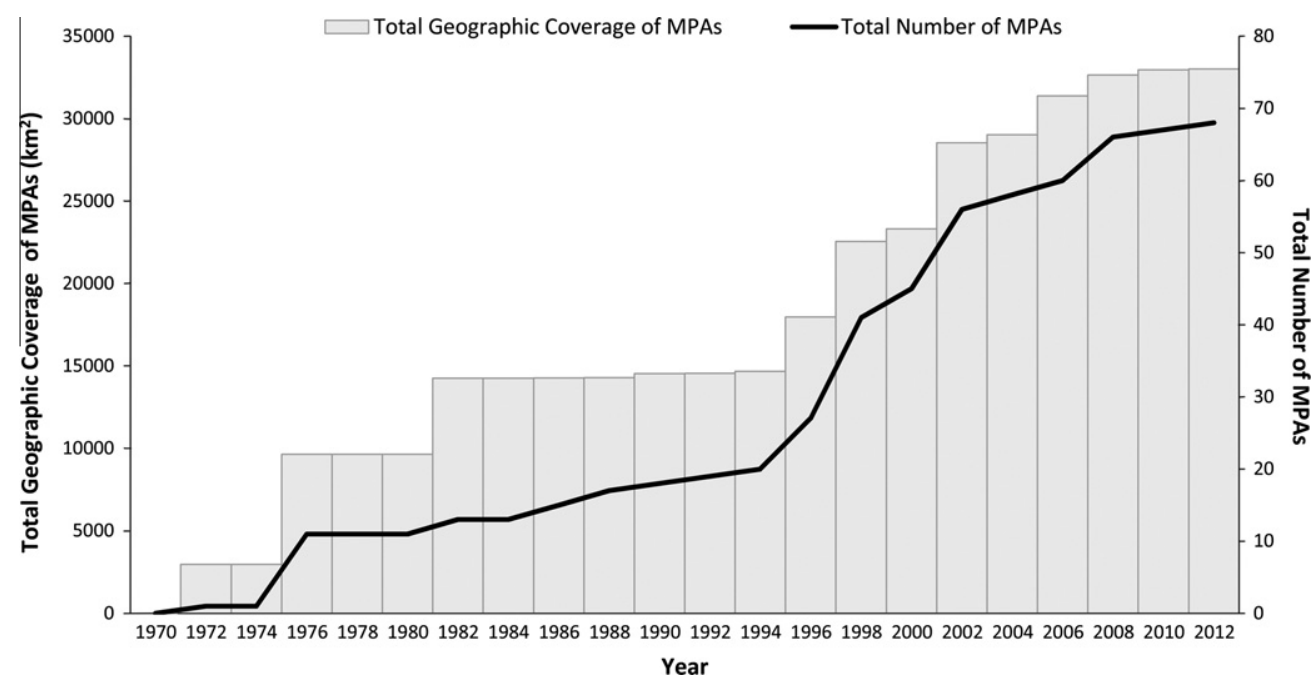

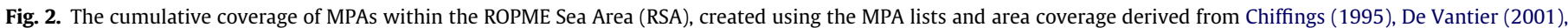
Klaus (2001), Krupp (2002), Wood (2007), IUCN and UNEP-WCMC (2010), ESO (2012) and Al-Cibahy (2012).

sensitive marine areas were identified in 1987 and a system of protected areas was proposed for Tarut Bay in 1990. The Jubail Marine Wildlife Sanctuary, the first MPA in the western Gulf, consists of two large coastal embayment systems and five offshore coral islands. The national authority responsible for MPAs is the Department of Protected Areas Planning, Saudi Wildlife Agency (SWA; formally the National Commission for Wildlife Conservation and Development (NCWCD)).

\subsubsection{State of Qatar}

The MPA list was validated by the national management authority in Qatar, the Private Engineering Office (PEO) (a government agency since 2004, under the auspices of the Emiri Diwan of Qatar) and the General Directorate of Nature Reserves (Ministry of Environment), and three MPA Scorecards were completed, covering six MPAs (one MPA Scorecard was completed for four of the islands). There are currently seven established MPAs in Qatar covering an estimated area of $673.4 \mathrm{~km}^{2}$ which is $11.6 \%$ of their territorial waters and 5.3\% of the EEZ (Table 3 and Fig. 1). No further sites have been proposed. The first MPA in Qatar (Khor Al-Odaid; or Khor Al Udeid) was gazetted in 1993 through the Ministry of Municipal Affairs and Agriculture Decree $N^{\circ} 78$ for 1993 where fishing was banned and has been proposed as a World Heritage site. Al Reem is designated as a UNESCO Man and Biosphere Reserve (2007) and includes mudflats and seagrass beds, and the Ras Ushairij Gazelle Conservation Park. All the islands of State of
Qatar are protected areas. Most of these islands are home to migratory birds. Al Thakira (or Al-Dakheera) is a mangrove forest. Qatar launched its National Biodiversity Strategy and Action Plan (NBSAP) under the CBD in 2004. This includes an element on PAs. The Supreme Council for Environment and Natural Resources (SCENR) developed a National Protected Areas Plan (2008-2013) in 2007 which calls for expansion of PAs including MPAs, improvement of management and enhancing of management capacity.

\subsubsection{United Arab Emirates}

The MPA list was not validated by the national management authority (Environment Agency - Abu Dhabi) in the UAE within the timeframe for this paper, but 7 MPA Scorecards were completed, and the remainder of the information was obtained from the literature. There are 15 MPAs in the UAE, covering $6946.3 \mathrm{~km}^{2}$, which is $22.4 \%$ of the territorial waters and $12.7 \%$ of the EEZ (Table 3 and Fig. 1) established under Emiri Decrees. Another 13 MPAs have been proposed. The first three MPAs in the UAE (Dibba, Dadna and Al Aqa) were established in 1995 on the east coast of the Fujairah Emirate. In 2001, Abu Dhabi declared the Marawah MPA, the largest in the region covering an area of $4255 \mathrm{~km}^{2}$ (declared a UNESCO Man and Biosphere Reserve (MAB) in 2007). Another important MPA in Abu Dhabi is Al Yasat declared in 2005. It is composed of a group of four islands and surrounding waters along the northern coast of the UAE which make up a $482 \mathrm{~km}^{2}$ no-take zone. The Bul Syayeef MPA was established in

Table 4

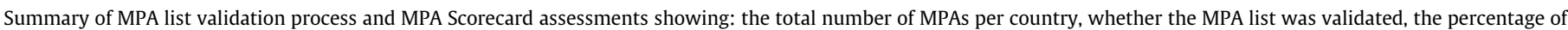
MPAs assessed, the total number of MPAs 'Designated' (or privately owned) or 'Proposed and the number of MPA Scorecard assessors.

\begin{tabular}{|c|c|c|c|c|c|c|c|}
\hline & \multicolumn{7}{|c|}{ MPA Scorecards completed } \\
\hline & No. of MPAs & MPA details validated ${ }^{a}$ & Total no. & $\%$ & No. designated/private & No. proposed & Number of assessors \\
\hline Bahrain & 7 & No & 0 & 0 & 0 & 0 & 0 \\
\hline Iran & 31 & Yes & 1 & 3.2 & 1 & 0 & 1 \\
\hline Iraq & 0 & NR & NR & NR & NR & NR & NR \\
\hline Kuwait & 30 & Yes & 30 & 100 & 7 & 23 & 1 \\
\hline Oman & 54 & No & 1 & 10 & 1 & 0 & 1 \\
\hline Qatar & 7 & Yes & $3^{\mathrm{b}}$ & 85.7 & 6 & 0 & 2 \\
\hline Kingdom of Saudi Arabia & 16 & No & 1 & 6.25 & 1 & 0 & 1 \\
\hline \multirow[t]{2}{*}{ United Arab Emirates } & 28 & No & 6 & 21.4 & 6 & 0 & 3 \\
\hline & 173 & & 45 & 26.01 & 22 & 23 & 9 \\
\hline
\end{tabular}

\footnotetext{
a Validation by representative from the relevant management authority.
}

b One MPA Scorecard was completed for 4 MPA sites (islands). 
2007. Dubai has demonstrated less commitment to MPA establishment. Legal status was given to the Jebel Ali Marine Reserve (1998) to protect what was once one of the Gulf's richest coral reef ecosystems (Riegl, 1998). However, most of this reef area was lost (over $8 \mathrm{~km}^{2}$ ) due to extensive coastal development in the early $2000 \mathrm{~s}$ (Burt et al., 2008, 2010).

\subsubsection{MPA Scorecard results}

There were nine respondents that completed MPA Scorecard assessments (three management authority assessors and six independent assessors) covering $26.0 \%$ of all the MPAs in the region (45 of 173 MPAs). The MPAs assessed included 34.4\% of the 'Designated' MPAs (22 out of 64 MPAs) and $21.1 \%$ of the 'Proposed' MPAs (23 out of 109 MPAs) (Table 4). The response rate varied between countries and assessors: management authority assessors completed MPA Scorecards for all MPAs in Kuwait (30 MPAs) and nearly all MPAs in Qatar (6 MPAs), six independent assessors completed MPA Scorecards for 9 sites within four countries (Iran 1 MPA, Oman 1 MPA, UAE 6 MPAs, and Saudi Arabia 1 MPA). No MPA Scorecards were completed for Bahrain (Table 4). With the tight deadline required for this survey, more responses are anticipated in due course.

Given that not all MPAs were assessed, it was not possible to complete the analysis at the national level for all countries, so the results were pooled and analysed at the regional level. Furthermore, given that only one country had completed the MPA Scorecard for both 'Proposed' and 'Designated' sites, all 'Proposed' sites were excluded from the analysis. Only those MPAs that the Governments had agreed to gazette or which were privately owned were included in the analysis. This meant that although 45 MPA Scorecards were completed, only 22 MPA Scorecards were included in the regional analysis. Scores for the main questions, the average scores for each of the six main management stages (A$F$ ), and the Overall Scores from these 22 MPAs were thus interpreted as being representative of other MPAs in the RSA region. While the MPAs included in the analysis may not be wholly characteristic of all the others in the region, the results presented here give a best first impression of the current effectiveness of MPAs in the RSA.

The ranks (0-3) achieved for each of the main questions are shown in Fig. 3. Average scores for all 22 MPAs for all six stages (A-F) included in the MPA Scorecard and the Overall Score are shown in Fig. 4a. The Overall Score for management effectiveness of the MPAs assessed within the RSA ranged from $11.5 \%$ to $58.1 \%$, with an average of $34.7 \%$ ( \pm 3.2 Standard Error, SE). Average scores were lowest for 'Planning' $(25.1 \% \pm 5.3)$, followed by 'Process' $(27.1 \% \pm 2.7)$, 'Outcomes' (31.7\% \pm 3.7$)$, 'Outputs' (32.3\% \pm 4.9$)$, 'Inputs' $(34.5 \% \pm 5.3)$ and highest for 'Context' $(49.3 \% \pm 3.9)$. Further details for each of the six stages covered in the MPA Scorecard stages and the main questions are presented below.

The average Overall Score for management effectiveness for MPAs assessed $(N=22)$ in each country in the RSA is shown in Fig. $4 \mathrm{~b}$. The figure shows the average where more than one MPA was assessed or just the Overall Score, where only one MPA was assessed. The Overall Score for management effectiveness of MPAs assessed in Kuwait $(n=7)$ ranged from $12.6 \%$ to $58.1 \%$ with an average of $43.7 \%( \pm 6.9, \mathrm{SE})$, in Qatar $(n=6)$ from $29.5 \%$ to $35.9 \%$ with an average of $30.9 \%( \pm 0.9, \mathrm{SE})$, and in UAE $(n=6)$ from $11.5 \%$ to $46.8 \%$ with an average of $18.7 \%( \pm 6.2, \mathrm{SE})$. The Overall Score for 1 Scorecard in Saudi Arabia is $52.6 \%$, in Oman is $43.8 \%$, and in Iran is $51.1 \%$.

Fig. 5a shows the current status of all the MPAs in RSA. Of the total of 173 MPAs in the RSA, only 9 have been 'Designated' as well as 'Adopted', 55 have been 'Designated', and the majority (88) have been "Proposed". For 21 of the MPAs in the RSA, the current status is "Unknown". This information was also not verified by the national MPA authority. The ranking (High, Moderate, Low) of the 'Overall Score' for management effectiveness for all the MPAs scorecards completed ( $N=45$ scorecards) for the MPAs assessed $(N=22$ MPAs) is shown in Fig. 5b. It also shows the results from scorecards completed for 'Proposed' MPAs which totals 23 (these were not ranked). None of the MPA scorecards scored High (>75\%), 16 scored Moderate (25-75\%), and 6 scored Low (0-25\%).

3.2.8.1. Context: Where are we now? Assessment of important threats and the policy environment. The 'Context' section includes questions relating to the legal context, mechanisms for controlling human activities, staff capacities for enforcing regulations, awareness of the boundaries and demarcation status, research and monitoring activities and general stakeholder awareness. The ranking of each question is shown in Fig. 3. The total scores for 'Context' ranged from $19.2 \%$ to $76.9 \%$ and the average score was $49.3 \% \pm 3.9 \mathrm{SE}$, which was the highest score for all sections (Fig. 4).

Given the selection criteria applied, MPAs included in the analysis (17 MPAs) scored highly (rank 3) for Question 1 (Q01), as they had been legally gazetted or were privately owned (77.3\%). For the remainder of sites, the governments had agreed to gazetting, but the legal process had neither begun, or been finalised.

Nearly all of the MPAs (20 out of 22 MPAs) have some mechanisms for controlling unsustainable human activities (Q02), however: $9.1 \%$ have 'no mechanisms for control' (rank 0), 31.8\% have 'major problems' (rank 1); 45.5\% have 'some problems' in implementation (rank 2) and; only $13.6 \%$ of MPAs have effective mechanisms for implementing MPA regulations (rank 3). Staff capacity/resources (Q03) to enforce MPA legislation appears to be a constraint in all but one of the MPAs (4.6\%, rank 3), staff either have: 'no capacity/resources' (22.7\%) (rank 0), 'major capacity/resource constraints' (18.2\%) (rank 1), or 'acceptable capacity/resources but some deficiencies remain' (54.5\%) (rank 2). While 8 of the MPAs (36.4\%) have additional control mechanisms (e.g. volunteers, local community support), only 3 of the MPAs (13.6\%) reported that infractions were regularly prosecuted.

MPA boundaries (Q04) are 'appropriately demarcated and known by both the management authority and other stakeholders' in $36.3 \%$ of the sites (rank 3). Boundaries are 'known by the management authority and others but not demarcated' at $18.2 \%$ of sites (rank 2), 'only known by the management authority and no demarcated' at $40.9 \%$ of sites (rank 1 ) and not known by either the management authority and other at one site (4.6\% rank 0 ).

None of the MPAs are fully integrated into a larger coastal zone management plan (Q05), and although this process is underway for $50.0 \%$ of the sites (rank 2), there has either only been 'some discussion' (22.7\%) (rank 1) or 'no discussion' of integration (27.2\%) (rank 0 ) for the remaining sites. Only 6 of the MPAs (27.3\%) were considered part of a broader MPA network, and only 2 MPAs (9.1\%) were considered to be part of a network which reflected the biogeographic variation in a marine eco-region.

Resource inventories and baseline data, describing the biological, socio-cultural and economic conditions (Q06), were considered to be sufficient for key planning and decision making in $45.5 \%$ of MPAs (rank 2), but the necessary survey work is only being maintained in $22.7 \%$ of MPAs (rank 3). Resource inventories and baseline data were insufficient for $18.2 \%$ of MPAs (rank 1 ) and entirely lacking for $13.6 \%$ of the sites (rank 0 ).

Stakeholder awareness (Q07) of marine resource conditions also appears to present a major challenge to the effectiveness of the MPAs in the RSA. At half of the sites, only ' $25-50 \%$ of stakeholders' were considered to be aware or concerned about marine resource conditions and threats (rank 1), and a further $22.7 \%$ of sites considered that ' $<25 \%$ of stakeholders' were even aware of the threats (rank 0). 


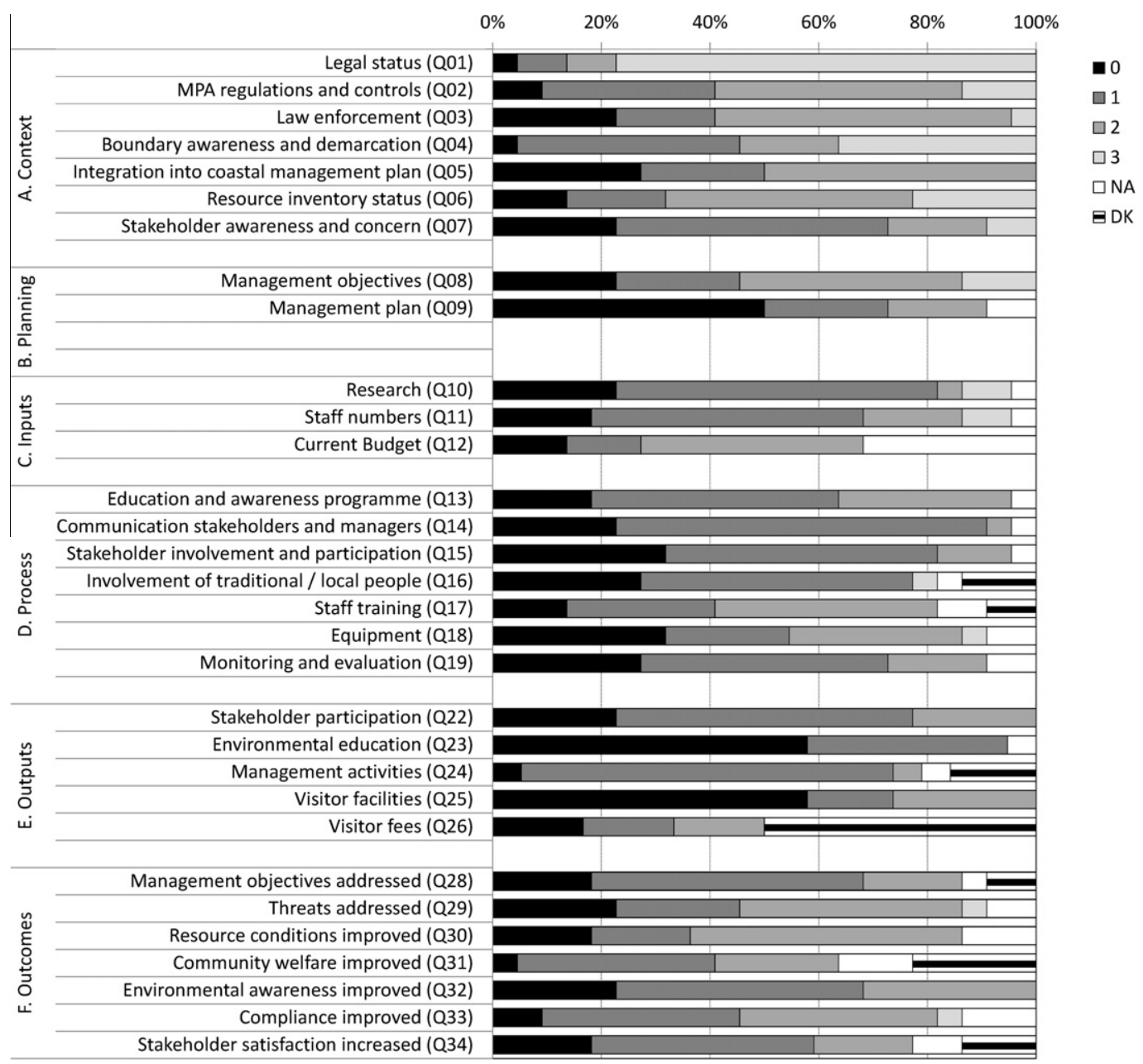

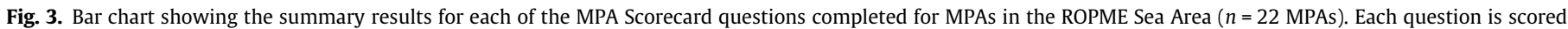
from low $(0)$ to high (3), or 'NA' if the question was not applicable and 'DK' if the assessor did not know the answer.
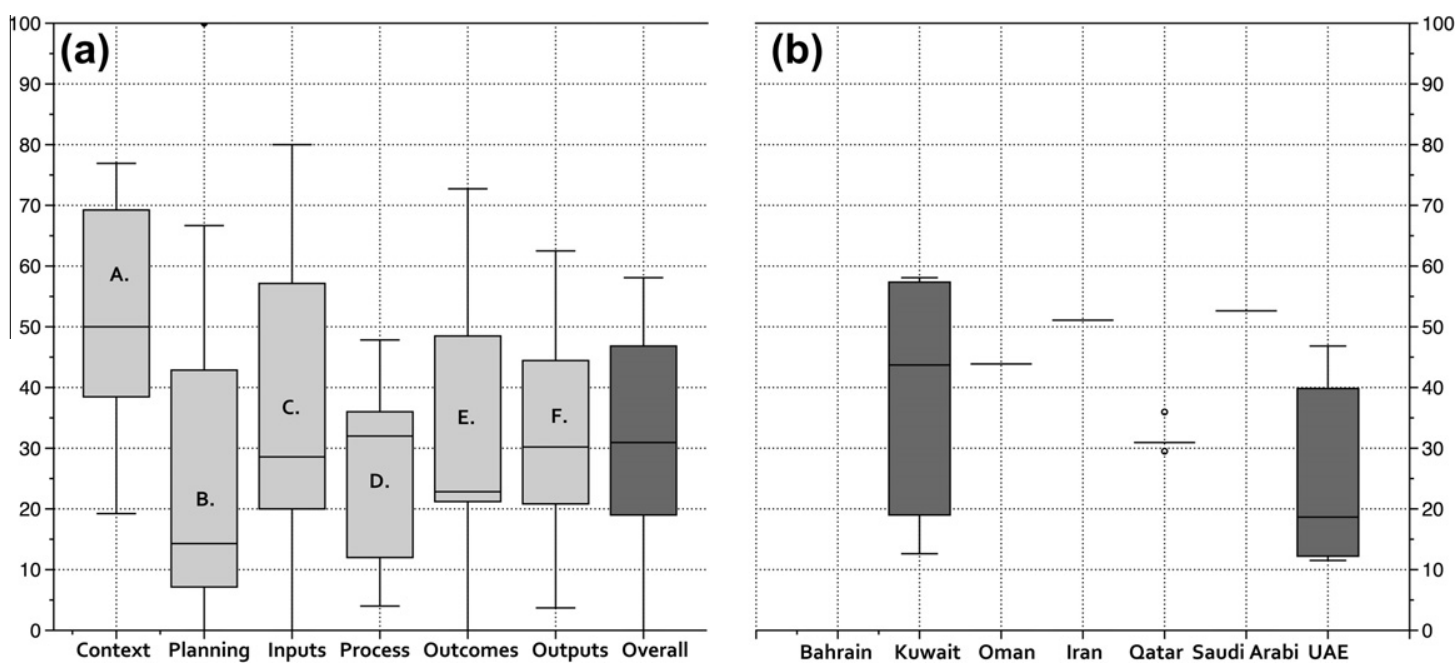

Fig. 4. (a) Box plot showing the average management effectiveness scores for MPAs in the ROPME Sea Area ( $n=22$ MPAs). Results show the average for each of the six main stages in the MPA Scorecard (A. Context, B. Planning, C. Inputs, D. Processes, E. Output and F. Outcomes) and the Overall Score for all stages. (b) Box plot showing the average Overall Score for management effectiveness for each country in the ROPME Sea Area. Results show the average of the where more than one MPA was assessed (e.g. Kuwait $=7$, Qatar $=6$ and $\mathrm{UAE}=6$ ), or just the Overall Score, where only one MPA Scorecard was assessed.

3.2.8.2. Planning - Where do we want to be? Assessment of MPA design and planning. The questions in the 'Planning' stage relate to MPA design, management objectives and plans, and there are also a series of additional questions related to the different dimensions of the management planning process. The ranking of each question is shown in Fig. 3. The scores for 'Planning' range from $0 \%$ to $100 \%$ 

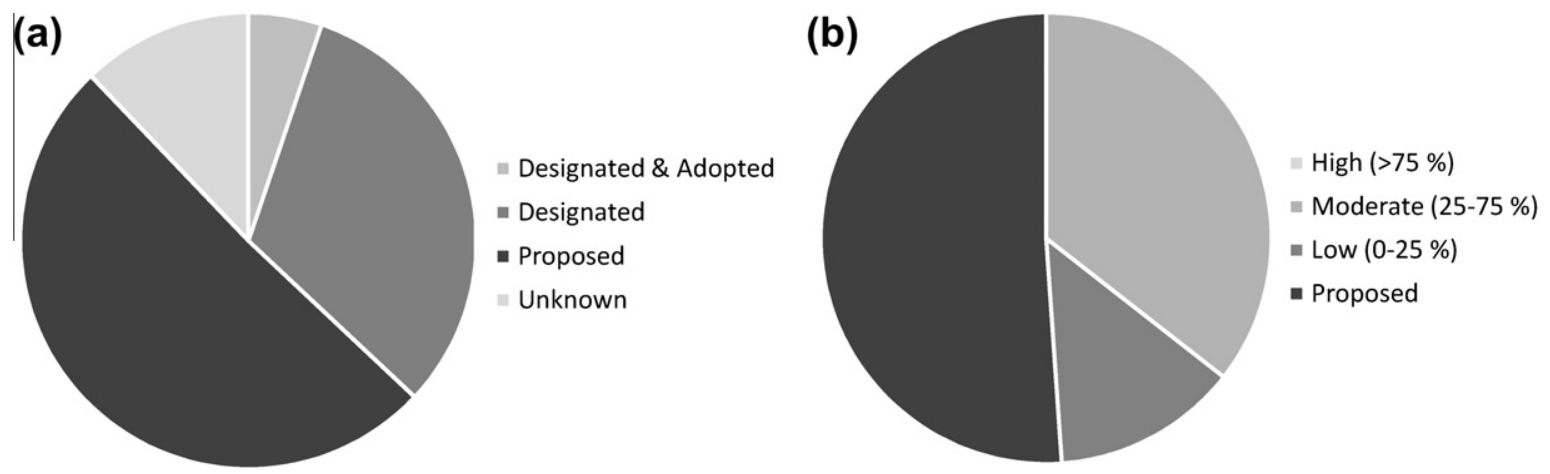

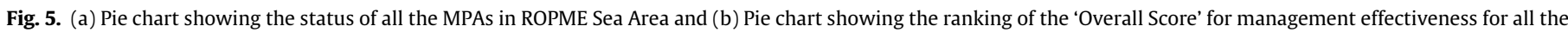
MPAs assessed ( $N=22$ MPAs, the number of 'Proposed' MPAs for which Scorecards were completed are included for completeness, but not ranked).

and was on average $25.1 \% \pm 5.3$, which was the poorest Overall Score for all of the six stages (Fig. 4a).

Management objectives (Q08) have been discussed and agreed for most of the MPAs that were assessed, however, only $13.6 \%$ are being managed to meet these objectives (rank 3). Objectives have been 'agreed but not implemented' at $22.7 \%$ of sites (rank 2 ), and are 'only being partially implemented' at a further $40.9 \%$ of the sites (rank 1). The remainder of the MPAs (22.7\%) have no firm objectives (rank 0). Moreover, half of the MPAs assessed do not have management plans (rank 0) (Q09), which is a fundamental gap. For the other sites, management plans are either in preparation (rank $1,22.7 \%$ ) or exist and are only partially or not implemented (rank 2, 18.2\%). None of the sites have a management plan which is being fully implemented (rank 3 ).

Few points were scored by any of the MPAs assessed for the additional questions in this section: Only two MPAs $(<10 \%)$ have a long term master plan (at least 5 years). Stakeholder participation in management decision making is generally very low $(<5 \%)$, and not typically equitable, in terms of representation from the various ethnic, religious and user groups, or genders $(<10 \%)$. Socio-economic impacts have only been taken into account in the planning process at $13.6 \%$ of MPAs. Local values, traditional practices, cultural features and historical sites and monuments were taken into consideration in the planning process at $22.7 \%$ of MPAs. The results of monitoring, research and evaluation are typically routinely incorporated into planning at only $22.7 \%$ of MPAs and only one of the MPAs assessed has an established schedule for the periodic review and updating of the management plan.

3.2.8.3. Inputs: What do we need? Assessment of resources needed to carry out management. The questions in the 'Inputs' section relate to assessment of the resource needs for management in terms of research and carrying capacity studies, as well as staff numbers, and budget allocations. The ranking of each question is shown in Fig. 3. The scores for 'Inputs' ranged from $0 \%$ to $80 \%$, and the average Overall Score at this stage was $34.5 \% \pm 5.3 \mathrm{SE}$, which was the second highest ranking out of all of the stages after 'Context' (Fig. 4a).

Management-oriented survey and research work (Q10) is not being undertaken in $22.7 \%$ of the MPAs assessed (rank 0 ), or is only conducted on an ad hoc basis at a further $59.1 \%$ of the MPAs (rank 1). One MPA had a comprehensive research and survey programme which was not directed towards the needs of management (rank 2 ), and only two of the MPAs had a comprehensive integrated programme of work which related to management needs (rank 3). An additional question on carrying capacity studies revealed that these had only been completed for 3 of the MPAs (13.6\%).

Staff numbers (Q11) are largely considered to be inadequate to manage the MPA (50\%) (rank 1), and 4 of these 'Designated' MPAs have no staff at all (18.2\%) (rank 0). Staff numbers were below optimal at $18.2 \%$ of sites (rank 2 ), and only considered to be adequate at two of the MPAs (rank 3). There was additional support from volunteers or the local community at 5 of the MPAs (22.7\%).

Budget was identified as a constraint for most of the MPAs assessed (although independent assessors were unable to answer this question for 7 MPAs). There was no budget for 3 MPAs (13.6\%) (rank 0), for another 3 MPAs (13.6\%) it was inadequate (rank 1). For 9 MPAs (40.9\%) the available budget was sufficient but could be improved (rank 2). Perhaps unsurprisingly, none of the MPAs assessed had a sufficient budget to meet all management needs (rank 3). The budget was not considered to be secure on a multi-year basis for any of the MPAs, and only two of the MPAs had alternative sources of funding other than that provided by the government (e.g. NGO contributions, taxes, fees, etc.).

\subsubsection{Process - How do we go about management? Assessment of} the way in which management is conducted. The questions in the 'Process' section relate to education and awareness raising activities, communication between stakeholders and managers, stakeholder engagement in management decisions, involvement of local people in decision making, staff training, equipment and monitoring and evaluation processes. The ranking of each question is shown in Fig. 3. The Overall Scores for 'Process' were particularly low for the MPAs assessed, and ranged from $4 \%$ to $47.8 \%$. The average Overall Score for this stage was $27.1 \% \pm 2.7 \mathrm{SE}$, the second lowest of all six stages after 'Planning' (Fig. 4a).

There is no education and awareness program (Q13) for $18.2 \%$ of MPAs assessed (rank 0), and only limited or ad hoc education and awareness for a further $45.5 \%$ of the MPAs (rank 1 ). Although $31.8 \%$ have a planned programme, these still had serious gaps (rank 2) and, no MPAs have an effective education programme (rank 3). There is no communication (Q14) between stakeholders and managers at $27.7 \%$ of MPAs (rank 0 ) and only weak or irregular communication at a further $68.2 \%$ of MPAs (rank 1 ). Only one MPA has a planned communication programme, but it is not implemented (rank 2). Also only one of the MPAs communicated with other MPA managers for example, with respect to exchange of best practices.

Stakeholder involvement and participation in decision making is also constrained (Q15) and there is no input at 31.7\% of sites (rank 0). For $50 \%$ of the MPAs, although there is a mechanism in place for stakeholders to contribute towards discussions, there is no direct involvement in decision making (rank 1). Stakeholders directly contribute towards some decisions in 3 of the MPAs (13.6\%) (rank 2). None of the MPAs provided mechanisms to allow stakeholders to fully engage and contribute towards management decisions (rank 3). Similarly, although Local residents or regular users of the MPA have some input into discussions relating to 
management, at 50\% of MPAs, they have no direct involvement (Q16). None of the MPAs have financial contributions/agreements between MPAs and tourism operators to recover MPA resource rents for local benefits.

Staff training and skills (Q17) are considered to be adequate at $40.9 \%$ of the MPAs assessed (rank 2), but they are considered low relative to the needs of the MPA at a further $27.3 \%$ of sites (rank 1 ), and completely lacking at a further $13.6 \%$ of sites (rank 0 ). There is no equipment or facilities (Q18) at $31.8 \%$ of sites (rank 0), provision is inadequate at a further $22.7 \%$ (rank 1 ) and only adequate and maintained at $31.8 \%$ (rank 2). Only one of the MPAs had adequate equipment and facilities that were well maintained (rank 3).

Monitoring and evaluation of biophysical, socioeconomic and governance indicators (Q19) is absent (27.2\% of MPAs rank 0) or ad hoc for most sites (45.5\% of MPAs rank 1 ). At the remainder of the sites where there is monitoring (18.2\%), the results tend not to be used to inform management (rank 2). None of the sites had a good monitoring and evaluation system, which were well implemented and used in adaptive management (rank 3). None of the MPAs participate in national or international environmental monitoring programs (e.g. Global Coral Reef Monitoring Network) and there are no emergency response capabilities in place to mitigate impacts from non-threats.

3.2.8.5. Outputs - What were the results? Assessment of the implementation of management programs and actions; delivery of products and services. Questions in the 'Outputs' section relate to changes in the 'Context' indicators since the last assessment, or progress over the last 3 years if this is the first time the assessment is being completed. For new MPAs, assessors were informed that they may need to skip this section. The ranking of some of the question in this section are shown in Fig. 3 (excluding Q20 and Q21). The Overall Scores for the 'Outputs' ranged from $0 \%$ to $72.7 \%$, and the average Overall Score this stage was $32.3 \% \pm 4.9$ SE (Fig. $4 a$ ).

The context indicators for those MPAs included in the assessment have improved as followed: the legal status has improved in $22.7 \%$ of MPAs (NA $=18.2 \%$ ), regulations have improved in $31.8 \%$ of MPAs $(\mathrm{NA}=13.6 \%$ ), law enforcement has improved in $31.8 \%(\mathrm{NA}=13.6 \%)$, boundary demarcation has improved in $27.3 \%$ of MPAs (NA $=4.5 \%$ ), integration of the MPA into broader coastal management plans has improved in $18.2 \%$ of MPAs (NA $=13.6 \%$ ), resource inventories have improved in $31.8 \%$ of MPAs (NA 13.6\%) and stakeholder awareness has improved in $36.4 \%$ of MPAs (NA $=13.6 \%$ ). Signs are now available in $54.5 \%$ of MPAs, moorings are available in $45.5 \%$ of MPAs, and education materials are available for $45.5 \%$ of MPAs.

Stakeholder participation mechanisms (Q22) are present but not sufficient for $54.5 \%$ of MPAs and environmental education (Q23) is absent from 50\% of MPAs, or insufficient for $31.8 \%$ of MPAs. Management activities have been undertaken to address the main threats (Q24) in 59.1\% of the MPAs. Only one of the MPAs indicated that management activities have not improved (NA $=3$ MPAs, 13.6\%). All MPAs assessed indicated that there was a need for staff to receive more training in how to meet the objectives of management and to address specific threats.

There are no visitor facilities at 50\% of MPAs (rank 0) (Q25), $13.6 \%$ have facilities that are inappropriate or under construction (rank 1), while $22.7 \%$ need improvement (rank 2). None of the MPAs had good visitor facilities. Visitor fees (Q26) were not considered applicable for $27.2 \%$ of MPAs. For two of the MPAs (9.1\%) there is a fee system, but the fees are not collected (rank 0). For another two MPAs, there are fees but they go straight to central government (rank 1) whereas another two MPAs have a fee system but the money goes to the local authority (rank 2). None of the MPAs assessed have a fee system where the money collected goes directly towards supporting the management of the MPA (rank 3).
3.2.8.6. Outcomes - What did we achieve? Assessment of the outcomes and the extent to which they achieved objectives. The questions in the 'Outcomes' section relate to achievements in terms of management objectives, addressing threats, status of resource conditions, community welfare, environmental awareness, compliance and stakeholder satisfaction. The ranking of each question is shown in Fig. 3. The Overall Scores for 'Outcomes' were generally low and ranged from $3.7 \%$ to $62.5 \%$, and the average Overall Score at this stage was $32.3 \% \pm 5.3 \mathrm{SE}$ (Fig. $4 \mathrm{a}$ ).

MPA objectives ( $Q 28$ ) have not been addressed at $18.2 \%$ of sites (rank 0 ), only partially addressed at $50 \%$ of sites (rank 1 ) and sufficiently addressed at $18.2 \%$ (rank 2). None of the MPAs assessed were considered to have significantly addressed the objectives (rank 3). Threats (Q29) have increased at $22.7 \%$ of sites (rank 0), stayed the same at $22.7 \%$ of sites (rank 1 ), somewhat reduced at $40.9 \%$ of sites (rank 2) and largely reduced at only one site (rank 3 ). Resource conditions within the MPAs (Q30) have declined at $18.2 \%$ of sites (rank 0 ), stayed the same at $18.2 \%$ of sites (rank 1 ), improved slightly at $50 \%$ of sites (rank 2). None of the MPAs assessed were scored as having significant improvement in resource conditions (rank 3).

Community welfare, livelihoods and standards of living (Q30) were scored as not relevant (NR) at $22.7 \%$ of sites or as 'do not know' at $13.6 \%$ of sites. Livelihoods and living standards were considered to have remained the same at $36.4 \%$ of sites (rank 1 ), improved somewhat at $22.7 \%$ of sites (rank 2), but none had improved significantly (rank 3). MPA management was only considered to be compatible with local culture and traditional practices at $18.2 \%$ of MPAs. Resource use conflicts have only been reduced at a single MPA. Benefits from the MPAs were only considered to be equitably shared at $13.6 \%$ of MPAs. Whereas the nonmonetary benefits of the marine resources to society has been maintained or enhanced at $13.6 \%$ of MPAs.

Environmental awareness of resource conditions, threats and management activities (Q32) has declined at 22.7\% of MPAs (rank 0 ), remained the same at $45.5 \%$ of MPAs (rank 1 ), and only improved somewhat at a further $31.8 \%$ (rank 2). Compliance appears to be moderate to good. Less than $10 \%$ of the MPAs assessed had $<25 \%$ of users complying with regulations (rank 0 ), where $36.4 \%$ of MPAs had $25 \%-50 \%$ compliance (rank 1) and $36.4 \%$ of MPAs had $50-75 \%$ compliance (rank 2 ). Only one site reported $>75 \%$ compliance (rank 3). Stakeholder satisfaction was generally low. For $40.9 \%$ of MPAs only $25-50 \%$ of stakeholders were satisfied with the process and outputs of the MPA (rank 1). One site reported that stakeholders felt that they were able to effectively participate in management decisions, or were adequately represented in the MPA decision-making processes.

\subsection{Protection of special sites (UNESCO WHS, BS, RAMSAR) and birds areas}

This region hosts numerous unique, rare and some endangered marine species including the dugong (Dugon dugon), marine turtles, sharks, dolphins and sea birds. Overall, international recognition of MPAs in the RSA is low. Only a few of the crucial habitats that support these species (mangroves, wetlands, salt flats, seagrass, coral reefs) have been designated as internationally recognised protected areas under international conventions such as UNESCO Man and Biosphere Reserves (MAB), UNESCO World Heritage Sites (WHS) and Ramsar Convention. UNESCO MABs aim to reconcile nature conservation and sustainable development (Table 2). The first two UNESCO MAB reserves in the region were established in 2007 at Marawah in UAE and Al-Reem in Qatar. Other areas under consideration for the UNESCO MAB include Khor Kalba in Sharjah UAE, established in 2001, and the Hawar Islands, established in Bahrain in 2002. UNESCO WHS sites can be cultural, 
natural, or both, and have a globally unique value for mankind. Although the RSA has a variety of candidate sites, there are currently no WHS sites in this region. There are 7 (coastal) Ramsar sites in the region (Table 2); the Ramsar Convention (1971) aims at the conservation and wise use of wetlands and their resources, but the definition is such that it also includes areas of corals and other important marine habitats.

This region is also an important region for numerous species of migratory birds. There are currently 90 Important Bird Areas (IBAs) in the RSA (these are not all reflected in Table 2; Birdlife International, 2012a) that exist on either coastal or sea habitats, including uninhabited islands (Tayefeh et al., 2011). An IBA is an internationally agreed upon location for active conservation and is established based on the presence of bird species at risk for global extinction, or whose populations are potentially irreplaceable (Birdlife International, 2012b). These sites are protected to sustain healthy populations of birds and provide satisfactory habitat during migration. Their distribution is highly varied in each RSA country, while most countries have several sites (Bahrain (3), Kuwait (2), Qatar (5), Iraq (2)), the UAE has 10 and Oman has as many as 30 . Despite the fact that only a quarter of these sites have legal protection, (Birdlife International, 2012c), there are several areas which cross over with important marine area. Promoting internationally recognised IBAs can synergistically enhance marine conservation efforts and lead to financial benefits (eco-tourism, scientific studies, governmental and donor funding opportunities) throughout the RSA.

\section{Discussion}

\subsection{Management effectiveness of the MPAs in the RSA}

The results presented here provide the first regional assessment of management effectiveness of MPAs in the RSA. The number, extent and status of MPAs within the whole RSA is presented, building upon the results of earlier regional studies (Chiffings, 1995), and for parts of the region (Krupp, 2002; Al-Cibahy et al., 2012), and an overview of the most salient obstacles to realising an effective network of MPAs within the RSA is provided. While some of the findings are daunting, this new information arms decision makers and conservation planners in the RSA with a greater understanding of the magnitude of the task ahead and the urgency with which it needs to be tackled.

A total of 173 MPAs were identified in the RSA, 64 of which are 'Designated' and 109 of which are 'Proposed'. While the standalone value of a list of MPAs in terms of assessing the effective level of protection is questionable (Roff, 2005; Mora and Sale, 2011), such a list is a fundamental prerequisite to any assessment of status or progress towards international targets. The 'Designated' MPA coverage as a percentage of the EEZs of each country ranged from $0 \%$ to $12.73 \%$ in the RSA, and the average coverage was $5.38 \%$ of the EEZs protected, which is lower than has been achieved in other regions. If the number of 'Proposed' MPAs were included, this figure would increase to $8.1 \%$ of the EEZs protected, which is still below the $10 \%$ CBD target. These results appear more positive when compared to the global statistics, which estimate that only $2.86 \%$ of EEZs are currently protected (Spalding et al., 2010). The results also indicate progress: Krupp (2002) previously estimated that $5 \%$ of the Gulf's surface area was protected and Al-Cibahy et al. (2012) estimated that $7.2 \%$ of the Gulf was protected, including 'Proposed' MPAs. Protection of territorial waters is higher, with an average of $10.75 \%$ protected by 'Designated' MPAs, and $16.25 \%$ including 'Proposed' MPAs. It should however be remembered that the area coverage figures are likely to be a overestimation for some countries, as the area cited in the literature rarely distinguishes between terrestrial and marine components of the MPAs.
The MPA Scorecard assessment provides a good first impression of the current level of management effectiveness of MPAs in the RSA and the major gaps. Overall Scores for management effectiveness ranged from 11.5 to 58.1, and the average Overall Score for the MPAs assessed was 34.7\% ( \pm 3.2 Standard Error, SE) which, if scaled at low $(0-25 \%)$, moderate $(25-75 \%)$ to high $(>75 \%)$ scores, would fall in the lower end of a moderate score. Using the same scaling, the 'Planning' and 'Process' stages ranked as low, while the 'Context', 'Inputs', 'Outputs' and 'Outcome' stages ranked as moderate. Overall some of the weaknesses identified in MPAs in the RSA include: (1) Many more MPAs have been 'Proposed' than actually gazetted. For those that have been 'Designated' or for which gazetting is underway there is; (2) poor enforcement of regulations, due to staff capacity and resource constraints; (3) inadequate boundary demarcation (often only the management authority knows the location of boundaries); (4) infrequent prosecution of infractions; (5) weak integration of MPAs into a broader ICZM programme; (6) poor representation and planning for MPA networks which reflects the bio-geographic variation; (7) low stakeholder awareness of the value of marine ecosystems; (8) a lack of clearly defined management objectives; (9) a lack of management plan (for $50 \%$ of sites); (10) no long term planning for financial sustainability of the MPA; (11) no effective mechanisms to supplement the 'core' budget through levying user fees; (12) weak participation of and communication with local stakeholders, traditional communities, and local marine resource users; (13) poorly designed and ad hoc monitoring, survey and research programs, which are not designed to inform adaptive management and decision making; (14) insufficient staff numbers; (15) poor facilities and equipment for management and visitors and; (16) limited education and awareness activities.

The number of 'Proposed' MPAs in the RSA typically far exceeds the number of 'Designated' MPAs (e.g. Kuwait 24 versus 6, and Saudi Arabia 15 versus 1). This is a global problem (IUCN and UNEP-WCMC, 2010), but the reasons why so many MPAs remain at the 'Proposed' stage in this region is particularly intriguing. Governance in the RSA is characterised by a strongly centralized decision-making process, which should make it easier to rapidly create new legislation and regulations (Van Lavieren et al., 2011). Furthermore, the high GDP and HDI values for the countries bordering the RSA (Table 1) indicate that a lack of financial resources is also not a likely cause. More importantly, this does not seem to have been a limiting factor in other less developed countries such as Kenya $(\mathrm{GDP}=29$ (M US\$), HDI =0.5) and Bolivia $(\mathrm{GDP}=17(\mathrm{M}$ US\$), HDI = 0.7), where progress towards CBD MPA targets $(12 \%$ and $19 \%$ for 2012 respectively) is greater than achieved by most ROPME countries (IUCN and UNEP-WCMC, 2010).

The fact that only two of the 22 MPAs $(<10 \%)$ assessed have a management plan (at least 5 years), is a fundamental yet revealing gap. A management plan is a good indicator of a Governments level of commitment to the active management of a protected area. Although management plans do not guarantee the specific commitments of funds and staff, they establish the basis for short-term or annual operational planning, and can be used to influence decisions about the allocation of resources (budgets). The fact that budget constraints were also identified as a limiting factor, and none of the MPAs assessed had a sufficient budget to meet all the management needs, is also revealing and indicative of a low level of commitment to marine protection. The low scores attained for the necessary equipment and facilities to adequately operate, control, monitor and manage MPAs are in line with this deficiency in financial resource allocation for MPAs. These deficiencies again emphasise the need for both long term management plans ( 5 year), and annual operational plans (1 year) which include the budget requirements for effective MPA operations. Such documents are the key tools that can be used to communicate with governments. 
Underlying this may be a need for government staff to be trained in management planning, but also a need to strengthen the fee system for MPAs in the RSA, which has scored low in this assessment.

Furthermore, while management objectives may have been agreed for the MPAs assessed, they are not being implemented or only partially implemented at the majority of sites within the RSA. Management objectives are normally determined at the outset of the planning process on the basis of the results of scientific surveys (species distribution, biomass, dispersal patterns, recruitment dynamics, trophic interactions, and critical habitat). The results of such baseline surveys are used to determine the size, shape, and intended overall goal and objectives of the MPA. This goal-setting or objective elaboration is a critical component of effective MPA design, and the establishment of targets against which progress toward the objectives can be measured (Agardy, 2000).

While most of the MPAs assessed appear to have sufficient baseline and resource inventory data that could be used in planning and decision making, for some this was either insufficient or totally lacking, which is a major concern. The results of these surveys may be used to inform objectives, however there is clearly a breakdown between the translation of survey results into management objectives and then into strategies and actions on the ground. Subsequent ongoing survey work is also inadequate. Only two of the MPAs had a comprehensive and integrated programme of research and monitoring. At other sites, monitoring and evaluation of biophysical, socioeconomic and governance indicators is absent or ad hoc and the results are not used to inform (adaptive) management. Such programmes would underpin and elucidate the setting of priority MPA management objectives and would help towards improved management effectiveness within the RSA.

The majority of MPAs in the RSA appear to have been identified historically, often as areas closed for hunting or fishing for a certain period of time. While newer MPAs seem to have been selected predominantly on the basis of their biodiversity value, rather than for fishery management purposes. There are only a few strict 'no-take reserves' (NTRs) in the RSA. Only one third of the MPAs indicated that boundaries were appropriately demarcated and known by both the management authority and other stakeholders, but at the remaining sites boundaries are not demarcated at all. This makes effective management and control of any activities within boundaries an impossible task.

Few of the MPAs in the RSA are embedded in a broader ICZM framework, a factor which would also ensure a more strategic, holistic and coordinated approach to management of the coastal zone and the strategic allocation of resources. Little consideration is given to the transboundary nature of the marine environment, influences from neighbouring countries, nor has there been region wide integrated planning and coordination of MPAs. Only 6 of the MPAs were considered to be part of a broader MPA network, and only 2 were considered to be part of a network which reflected the bio-geographic variation in a marine eco-region.

Also unclear is if there is adequate control of fisheries outside the boundaries of the MPAs, which is necessary for the MPA to have any fishery benefit. Crucial knowledge gaps include knowledge of spawning aggregations sites, migration routes, as well as key nursery areas for commercial fishery species. At the moment, with some exceptions (e.g. the Marawah MPA, UAE) most strictly marine MPAs (so not including the terrestrial ecosystems) in the RSA, are relatively small in size $\left(<600 \mathrm{~km}^{2}\right)$, and are located closely to the coastline (except for some off shore islands), which makes them vulnerable to coastal development impacts. At least some (larger) no-take zones need to be established in deeper waters of the RSA to protect large pelagic fish and highly migratory or vulnerable species such as marine mammals, as well as to offset fishing effort outside, particularly in the current situation where fishing effort is not reduced in conjunction with establishment of MPAs (Pauly et al., 2002).

The MPA selection process in the RSA appears to be neither technocratic (i.e. based on habitat and biophysical information) nor democratic (i.e. stakeholder driven). The low levels of awareness, inadequate communication and lack of engagement of marine resource users, local communities and other stakeholders in the decision making processes for management, are not surprising results. The strongly centralized decision-making processes common in the RSA, limit public participation and places the entire responsibility of environmental protection on government and its agencies. This non-participatory form of government reduces the need for environmental managers and decision makers to improve communication and outreach, and well structured, governmentled environmental education and awareness strategies are rare (Van Lavieren et al., 2011). The need to build awareness of and support for existing laws remains essential if management agencies are to have any chance to apply these laws effectively. Other factors that hamper effective policy implementation include frequently changing institutional structures and responsibilities, overlapping authority for environmental management, which results in slow or capricious decision-making processes (despite the process being centralised), and environmental institutions with limited power given to implement regulations (Van Lavieren et al., 2011). As observed by Khan (2007), the current status of coastal and marine ecosystems in this region reflects the constraints inherently associated with management largely driven by frameworks representing arbitrary jurisdiction of political units at both national and regional levels.

The major areas of concern outlined above will hamper progress towards the development of a regional MPA network, and achievement of CBD MPA targets. The situation is not likely to change until the need for and value of sustainable environmental management, as well as the risks associated with poor management, is recognized by government leaders. Such a change, while wholly feasible, will require a real commitment from the ROPME member states.

Our results do however also show that there are some strengths in the MPAs in the RSA. The 'Context' scores for the MPAs assessed were relatively high (49.3\%). The fact that nearly all of the MPAs have mechanisms for controlling unsustainable human activities in the MPA and that compliance scored highly are both encouraging and promising insights. Weak enforcement and compliance are two of the common constraints to the effective management of MPAs in other regions. These results suggest that MPAs in the RSA could potentially be highly effective were they to be legally 'Designated' and demarcated. All countries in the region have some kind of national legislation in place that provides for marine conservation and the establishment of MPAs. Generally, management regulations that currently govern protected areas in the RSA routinely forbid commercial fishing other than by artisanal fishermen using traditional gear, or the catch of any dugong, turtle, or marine mammal. However, there is little direct information concerning the effectiveness with which these regulations are enforced. There are major problems in implementing legal mechanisms and staff capacities and resources to enforce MPA legislation appears to be a constraint in all but one of the MPAs and only 3 of the MPAs reported that infractions were regularly prosecuted. Some improvements in the 'Context' indicators (legal status, regulations, law enforcement, boundary demarcation, integration into broader coastal management plans, resource inventories and stakeholder awareness) are also encouraging, however need to be verified further.

\subsection{Towards a regional MPA network for the RSA}

In consideration of the information and capacity requirment needed to fulfil the seven key criteria to build and design an 
effective MPA network for the RSA region, this study has elucidated some of the challenges related to: (1) Effectiveness. Other requirements for the other criteria are as follows: (2) Representativeness (i) classification and mapping of habitats at the national and regional level, (ii) identification of threatened, critical and unique areas, (iii) sites required by migratory species (e.g. sea turtles, sea birds); (3) Connectivity (iv) biological information (e.g. larval dispersal, population genetics) and (v) oceanographic information (e.g. currents); (4) Replication and (5) Resilience (v) risk analysis and (vi) monitoring and evaluation; (6) Adequacy (vii) size, shape and geographical placement and; (7) Governance Frameworks (viii) appropriate legal and institutional frameworks, increased staff capacity and resources for management planning and operations, (ix) broader management regimes and $(\mathrm{x})$ enhanced stakeholder and community involvement.

Throughout the region, while some of the basic information needed to establish an effective, coherent, and representative network of MPAs is available, there still gaps. First, although some countries have undertaken detailed habitat mapping studies (e.g., Abu Dhabi), few countries have determined the distribution and extent of the critical habitats within their EEZ's. So it is not yet possible to determine the percentage of habitats protected within existing MPAs or the additional area needed to achieve proportional coverage.

Most parts of the RSA have not been mapped at all or at best the mapping has been piecemeal for specific projects, and it is neither publically available nor centrally housed. Second, species distribution is also poorly documented and so is information on feeding and breeding areas and migration routes of key species. Third, more oceanographic information is needed on currents, gyres and eddies. This information will assist in predicting connectivity patterns. Limited information is available on larval dispersal, population genetics of different marine species (corals, fish, invertebrates), also for commercially important fishery species. This information is vital for the site selection of conservation areas. These deficiencies in knowledge are not all unique to this region and many management and zoning plans world-wide are drafted with incomplete knowledge.

There is the problem of a lack of transparency within the region, well described by Sheppard et al. (2010). Countries are encouraged to share some of the key data sets and store these in a regional database, to enable the development of a more transboundary and holistic management of the RSA. This would require the establishment of a region wide monitoring network to detect changes and the effects of management activities such as MPAs (Hamza and Munawar, 2009). Without monitoring there is no mechanism to prove an MPA, or indeed a network, is actually resulting in positive changes in marine ecosystem health and fisheries, making the establishment of new MPAs harder to 'sell'.

The goal of establishing an MPA network within the countries of the RSA should be to ensure the protection of a representative proportion of the marine habitats and communities, rare and vulnerable species or communities, as well as to maintain connectivity among sites to ensure the genetic flow and the maintenance of ecological viability and integrity of each site (UNEP-WCMC, 2008).

MPAs are not a panacea for all the threats to the marine enviroment, and need to be complemented by sound fisheries management outside the reserve as well as controls on human activities such as development, and pollution. As in other regions (Jameson et al., 1995, 2002; Bryant et al., 1998) the RSA MPAs are unlikely to be effective if they are subject to numerous, and often uncontrollable, external stressors from atmospheric, terrestrial, and oceanic sources, all of which can degrade the environment and compromise protection. As this region faces increasing threats from climate variability and change, it becomes even more essential to reduce other threats from rapid population growth, coastal development, and pollution to support natural resilience.
MPAs do however offer a starting point upon which stronger and more effective management may become established over time (Spalding et al., 2008). In some cases the simple step of enabling part of the ocean to be off limits, through for example NTRs, can reap tremendous benefits. The most effective configuration within this region would be a network of highly protected areas (meeting minimum size requirements), nested within a broader management framework. Such a framework could include larger, multiple-use reserves, managed for sustainable fisheries as well as the protection of biodiversity. The ideal MPA network would be embedded into coastal management regimes, to enable effective control of threats originating upstream and to maintain high water quality (e.g., Done and Reichelt, 1998).

Regional cooperation will be essential if priority environmental concerns are to be addressed successfully within the RSA. The RSA is however amongst the most politically sensitive water passages in the world and adopting a common approach to environmental management could prove challenging. Previous experience has shown that low levels of trust and transboundary cooperation, combined with deficiencies in institutional arrangements for bringing key stakeholders to the table, make it difficult for this region to develop integrated solutions. Nevertheless, the need for a Master Plan for developing an integrated network for MPAs in the RSA has been recognised (Krupp et al., 1996; Krupp, 2002). A binding legal instrument for the RSA may work to entice action, although many countries are already party to Multilateral Environmental Agreements (MEAs; such as MARPOL and UNCLOS) these have not always resulted in action (Khan and Price, 2002).

Critical to the success of such a network will be the implementation of a common, regionally agreed management framework and the development of the necessary technical capacity and expertise in the planning and management of MPAs. Regional networks of MPAs have the potential to add-value to conservation efforts by providing a politically 'neutral' platform for the development of transboundary knowledge networks for experience sharing and learning in resource management and conservation. ROPME countries could commence this process by strengthening the coordination of monitoring surveys, and improved communication about marine science within the region. ROPME countries could also follow the approach taken by the neighbouring Red Sea and Gulf of Aden region, where the Regional Organisation for Preservation of the Environment of the Red Sea and the Gulf of Aden (PERSGA), which established a regional network consisting of 12 key MPAs (Gladstone et al., 2003).

Finally, in formulating management regimes for MPAs or PAs, some countries have adopted the principles of the Hima system, the traditional community based system for sustainable management of natural resources (Gari, 2006). This traditional approach with origins over 2000 years ago was developed as an ancient acknowledgement of the scarcity of renewable resources. Hima encourages 'equitable sharing of resources, social inclusion, sustainable use, consultation, representation for decision-making, land management, management of scarce resources, rights of us, ethics, conservation, and poverty prevention' (Kilani et al., 2007). This concept could potentially be usefully applied in this region to build and create better understanding and acceptance of MPAs and promote the need to conserve and use marine resources wisely in support of sustainable economic development (Child and Grainger, 1990).

\section{Conclusions}

Threats to coastal and marine environments of the RSA continue to grow, while the overall health and status of many of these critical unique habitats is already at record low levels (Wilkinson, 2008; Sheppard et al., 2010). The only hope for the recovery of 
these wider ecosystems is to provide those remaining in good health with sufficient protection (WRI, 2008; WWF, 2008; Burt et al., 2010). MPAs that restrict all human activity (strictly protected areas or sanctuaries) may be the only tool left to safeguard the remaining coral reef, seagrass and mangrove habitats within this region. Such protection can be achieved through establishing a fully functioning, regional network of highly protected, appropriately sized and carefully distributed MPAs within the RSA, which covers a comprehensive ecologically representative proportion of habitats and diversity, to ensure resilience and connectivity. Several ROPME countries are currently developing or have adopted strategic national economic development plans (e.g., Bahrain Vision 2030; Qatar national vision 2030: and Plan Abu Dhabi 2030). While these plans predominantly focus on securing the economic future of the countries concerned, they also encompass land use and urban planning and environmental conservation. Firmly embedding marine conservation and management, and more specifically MPA networks, into the broader context of strategic plan helps empower mandated authorities and other organizations to engage more actively in shaping a better foundation for marine conservation (Al Cibahy et al., 2012). Several ROPME countries are in a unique position to be able to demonstrate global leadership in this regard, and given the availability of financial resources, to make better more informed choices. There is an excellent opportunity at this juncture in time for one or more of these nations to take the lead in promoting regional collaboration in marine spatial planning and conservation efforts, with the aim of establishing a comprehensive long-term regional initiative for holistic management of the RSA coastal and marine ecosystems. We recommend that ROPME countries:

(a) Establish a mechanism for regional collaboration in monitoring the status and health of critical marine habitats (coral reefs, seagrass beds, mangroves, water quality, etc.) and fisheries within the RSA and a regional database to house and share data.

(b) Initiate and support a comprehensive regional level economic valuation study of coastal and marine biodiversity, resources and habitats;

(c) Complete this preliminary effectiveness assessment of MPAs and use the results to complete the picture of status of MPAs, gaps and information needs for developing a regional MPA network;

(d) Conduct a transboundary diagnostic analysis (TDA) to identify high priority shared or transboundary coastal and marine issues within the RSA. Similar TDAs (often funded through GEF International Waters) have been conducted for Large Marine Ecosystems (i.e. Red Sea and Gulf of Aden, Mediterranean, Black Sea, South China Sea, Caribbean);

(e) Develop a Strategic Action Programme (SAP) based on findings of the TDA to identify ecosystem quality objectives (EQOs), targets and actions to address the proximal and root causes of priority transboundary issues. ROPME countries have adopted a Strategic Plan for Biodiversity (2011-2020) under the CBD framework and a recent workshop aimed at capacity building for implementation of the programme of work (POW) on protected areas (Dubai, April 2012), with representatives from the region. A comprehensive needs assessment was completed on capacity-building requirements, tools, and approaches for adapting and mitigating climate change, MPAs, governance, and valuation of ecosystem services. A POW should be developed specifically on MPAs aimed at supporting countries to achieve the CBD's 2020 target by establishing a representative network of MPAs. The POW could include the following components: (i) to assess the representativity and effectiveness of the existing MPAs; (ii) to design a network of MPAs representative of the ecological features of the region; (iii) to improve the management of the MPAs in the RSA; and (iv) to strengthen the governance systems of MPAs;

(f) Adopt the Regional Protocol on Biological Diversity and Specially Protected Areas.

To support (d and e), a Regional Activity Centre for (specially) protected areas (as established in the Mediterranean and Caribbean) should be established by the Contracting Parties to the Kuwait Convention and its Protocols in order to assist RSA countries in implementing the CBD Protocol concerning the conservation of biological diversity and the establishment of protected areas. RSA countries would need to host such a centre. ROPME already acts a the host institution for cooperation amongst the countries and could therefore play a key role in coordinating d) and e) and f) above, and for hosting a regional monitoring network, a regional (open access) shared database, and coordinating awareness and capacity building activities. This could be done together with regional (RECSO, WWF) and international (UNU, UNEP and UNESCO) partners, who will provide the RSA countries, upon their request, with the technical and, where possible, financial assistance to undertake the activities. Ultimate responsibility for implementation however, will lie with national authorities.

\section{Acknowledgements}

The authors are very grateful to the following individuals for their time and assistance in filling in score cards: Nouf Behbehani and Salah Almoudhi, Mahmoud Ali AlKhabbaz (Environment Public Authority, Kuwait); Laurence Vanneyre (Emirates Marine Environmental Group, Dubai), UAE; Rita Bento, (Emirates Diving Association (UAE), John Burt (New York University Abu Dhabi, UAE) and Kaveh Samini (Iran), Sultan Mohammad Al-Kuwari, Yousef I. AlHamar, Sayed J. Bukhari (General Directorate Of Nature Reserves, Qatar). Also thanked is Peyman Eghtesadi (Iranian National Center for Oceanography). The kind assistance provided by Layla Al-Musawi, Scientific Consultant ROPME, Kuwait, Mohamed Mustafa Eltayeb, West Asia IUCN Global Marine Program, Jordan, Benno Boer, UNESCO Doha, Qatar and Fareed Krupp, Director, Natural History Museum, Qatar Museums Authority, is greatly appreciated. Lisa Benedetti, Allesandra Gage and Naomi Stewart, UNU INWEH are thanked for their inputs and comments.

\section{References}

Agardy, T., 2000. Information needs for marine protected: scientific and societal. MOTE Symposium invited paper. Bull. Mar. Sci. 66, 875-888.

Al-Cibahy, A.S., Al-Khalifa, K., Boer, B., Samimi-Namin, K., 2012. Conservation of marine ecosystems with a special view to coral reefs in the gulf. In: Riegl, B.M., Purkis, S.J. (Eds.), Coral Reefs of the Gulf: Adaptation to Climactic Extremes, Coral Reefs of the World. Springer Science.

Belokurov, A., Besancon, C., Pavese, H., Burgess, N.D., Dudley, N., Stolton, S., Hockings, M., Leverington, F., Mackinnon, K., Whitten, T., 2009. New resources for assessing the effectiveness of management in protected areas. Oryx 43, 14

Birdlife International, 2012a. Data Zone. <www.birdlife.org/datazone/site/search> (accessed 08.05.12).

Birdlife International, 2012b. Important Bird Areas (IBAs). <www.birdlife.org/ action/science/sites> (accessed 08.05.12)

Birdlife International, 2012c. Middle Eastern Important Bird Areas. <http:// www.birdlife.org/action/science/sites/mideast_ibas/index.html> (accessed 08.05.12).

Bryant, D., Burke, L., McManus, J., Spalding, M., 1998. Reefs at Risk: A Map-based Indicator of Threats to the World's Coral Reefs. World Resources Institute, Washington, DC.

Burt, J., Bartholomew, A., Usseglio, P., 2008. Recovery of corals a decade after a bleaching event in Dubai, United Arab Emirates. Mar. Biol. 154, 27-36.

Burt, J., Feary, D.A., Usseglio, P., Bauman, A., Sale, P.F., 2010. The influence of wave exposure on coral community development on man-made breakwater reefs, with a comparison to a natural reef. Bull. Mar. Sci. 86, 839-859.

Burt, J., Al-Harthi, S., Al-Cibahy, A., 2011. Long-term impacts of bleaching events on the world's warmest reefs. Mar. Environ. Res. 72, 225-229. 
Convention on Biological Diversity (CBD), 2006. COP 8 - Eighth Ordinary Meeting of the Conference of the Parties to the Convention on Biological Diversity. Curitiba Decision VIII/15: Framework for Monitoring Implementation of the Achievement of the 2010 Target and Integration of Targets into the Thematic Programmes of Work. Annex 4. United Nations Environment Programme.

Convention on Biological Diversity (CBD), 2010. The strategic plan for biodiversity 2011-2020 and the Aichi Biodiversity Targets. In: Tenth Conference of Parties, UNEP/CBD/COP/DEC/X/2, Nagoya, Japan.

Chape, S., Blyth, S., Fish, L., Fox, P., Spalding, M., 2003. United Nations List of Protected Areas. IUCN - World Conservation Union and UNEP World Conservation Monitoring Centre, Gland, Switzerland and Cambridge, UK, 2003.

Chape, S., Harrison, J., Spalding, M., Lysenko, I., 2005. Measuring the extent and effectiveness of protected areas as an indicator for meeting global biodiversity targets. Philos. Trans. Roy. Soc. B 360, 443-455.

Chiffings, A.W., 1995. Marine Region 11 Arabia Seas. In: Kelleher, G., Bleakley, C. Well, S. (Eds.), A Global Representative System of Marine Protected Areas. Vol. III Central Indian Ocean, Arabian Seas, East Africa and East Asian Seas. Great Barrier Reef Marine Parks Authority, The World Bank, The World Conservation Union (IUCN), pp. 39-70.

Child, G., Grainger, J.A., 1990. A System Plan for Protected Areas for Wildlife Conservation and Sustainable Rural Development in Saudi Arabia. National Commission for Wildlife Conservation and Development. Riyadh and IUCN, Gland, $402 \mathrm{pp}$.

Center for International Earth Science Information Network (CIESIN), 2005. Gridded Population of the World, Version 3 (GPWv3): Coastlines. CIESIN, World Resources Institute, International Food Policy Research Institute. <http:// sedac.ciesin.columbia.edu/gpw>.

Cifuentes, M., Izurieta, A., de Faria, H., 2000. Measuring Protected Area Management Effectiveness. WWF, GTZ, IUCN, Costa Rica.

De Vantier, L., 2001. Regional action plan for the conservation of coral reefs in the Arabian region. In: Abuzinada, A.H., Joubert, E., Krupp, F. (Eds.), Proceedings of an International Symposium on the Extent and Impact of Coral Bleaching in the Arabian Region. Riyadh (5-9th 2000), Kingdom of, Saudi Arabia, pp. 271-272.

Done, T.J., Reichelt, R.E., 1998. Integrated coastal zone and fisheries ecosystem management: generic goals and performance indices. Ecol. Appl. 8, S110-S118.

Dudley, N., Stolton, S., Belokurov, A., Krueger, L., Lopoukhine, N., Mackinnon, K., Sandwith, T., Sekkhran, N. (Eds.), 2010. Natural Solutions: Protected Areas Helping People Cope with Climate Change. IUCN-WCPA, TNC, UNDP, WCS, The World Bank, and WWF; Gland, Switzerland/Washington, DC/New York

ESO, 2012. Environment Society of Oman. <http://www.eso.org.om/index/ list.php? categoryld $=305 \&$ Extension $=$ gif $>$.

Gari, L., 2006. A history of the hima conservation system. Environ. Hist. 12, $213-$ 228

Gell, F.R., Roberts, C.M., 2003. Benefits beyond boundaries: the fishery effects of marine reserves. Trends Ecol. Evol. 18, 448-455.

Gladstone, W., Krupp, F., Younis, M., 2003. Development and management of a network of marine protected areas in the Red Sea and Gulf of Aden region. Ocean Coast. Manage. 46, 741-761.

Hamza, W., 2000. Waste release into aquatic ecosystems: forms, impact, response and possible re-mediation. Terra in brief. J. Hydraul. Res. Center for Environ. CNR-Italy 3, 18-21.

Hamza, W., Munawar, M., 2009. Protecting and managing the Arabian Gulf: past, present and future. Aquat. Ecosyst. Health Manage. 12, 429-439.

Hockings, M., 2003. Systems for assessing the effectiveness of management in protected areas. Bioscience 53, 823-832.

Hockings, M., Stolton, S., Dudley, N., 2000. Evaluating Effectiveness: A Framework for Assessing the Management of Protected Areas. IUCN, Gland, Switzerland, and Cambridge, UK.

Intergovernmental Panel on Climate Change (IPCC), 2007. Climate change 2007: the physical science basis. In: Solomon, S., Qin, D., Manning, M., Chen, Z., Marquis, M., Avery, K., Tignor, M.M.B., Miller, H.L. (Eds.), Working Group I Contribution to the Fourth Assessment Report of the IPCC, Technical Summary (Global Climate Projections) (Chapter 10).

International Union for the Conservation of Nature and United Nations Environment Programme-World Conservation Monitoring Centre (IUCNUNEP-WCMC), 2010. The World Database on Protected Areas (WDPA), Cambridge, UK: UNEP-WCMC. <www.protectedplanet.net> (accessed 08.05.12).

International Union for the Conservation of Nature World Commission on Protected Areas (IUCN-WCPA), 2008. Establishing Marine Protected Area Networksmaking it Happen. IUCN-WCPA, National Oceanic and Atmospheric Administration and The Nature Conservancy, Washington, DC.

Jameson, S.C., McManus, J.W., Spalding, M.D., 1995. State of the Reefs: Regional and Global Perspectives. Background Paper, Executive Secretariat, International Coral Reef Initiative. US National Oceanic and Atmospheric Administration, Washington, DC.

Jameson, S.C., Tupper, M.H., Ridley, J.M., 2002. The three screen doors: can marine "protected" areas be effective? Mar. Pollut. Bull. 44, 1177-1183.

Kelleher, G., 1999. Guidelines for Marine Protected Areas. IUCN-The World Conservation Union, Gland, Switzerland.

Khan, N.Y., 2007. Multiple stressors and ecosystem-based management in the Gulf. Aquat. Ecosyst. Health. Manage. 10, 259-267.

Khan, N.Y., Price, A.R.G., 2002. Legal and institutional frameworks. In: Khan, N.Y. Munawar, M., Price, A.R.G. (Eds.), The Gulf Ecosystem: Health and Sustainability. Backhuys Publishers, Leiden, pp. 399-424.

Kilani, H., Serhal, A., Llewlyn, O., 2007. Al-Hima: A Way of Life. IUCN West Asia. <http://data.iucn.org/dbtw-wpd/edocs/2007-017.pdf> (accessed 08.05.12).
Klaus, R., 2001. Map of the MPAs of the Arabian region. In: Abuzinada, A.H., Joubert, E., Krupp, F. (Eds.), Proceedings of an International Symposium on the Exten and Impact of Coral Bleaching in the Arabian Region. Riyadh (5-9th 2000) Kingdom of, Saudi Arabia, pp. 1-2.

Krupp, F., 2002. Marine protected areas. In: Khan, N.Y., Munwar, M., Price, A.R.G. (Eds.), The Gulf Ecosystem Health and Sustainability. Backhuys Publishers, Leiden, pp. 447-474.

Krupp, F., Abuzinada, A.H., Nader, I.A. (Eds.), 1996. A Marine Wildlife Sanctuary for the Arabian Gulf - Environmental Research and Conservation Following the 1991 Gulf War oil spill. Riyadh \& Frankfurt, 511 pp.

Laffoley, D. d'A. (Ed.), 2008. Towards Networks of Marine Protected Areas. The MPA Plan of Action for IUCN's World Commission on Protected Areas. IUCN-WCPA, Gland, Switzerland.

Leverington, F., Costa, K.M., Courrau, J., Pavese, H., Nolte, C., Marr, M., Coad, L., Burgess, N., Bomhard, B., Hockings, M., 2010. Management Effectiveness Evaluation in Protected Areas - A Global Study, second ed. The University of Queensland, Brisbane, Australia.

Mackinnon, K., Dudley, N., Sandwith, T., 2011. Natural solutions: protected areas helping people to cope with climate change. Fauna Flora Int. 45, 461-462.

Mangubhai, S., 2003. Biological and Socioeconomic Monitoring Programmes and Assessment Recently Carried Out or Underway in MPAs in Selected Countries in the Western Indian Ocean: Kenya, Madagascar, Seychelles, South Africa and Tanzania. Unpublished Report, IUCN Eastern Africa Regional Office, Nairobi, Kenya.

McLeod, E., Salm, R.V., 2006. Managing Mangroves for Resilience to Climate Change. IUCN, Gland, Switzerland.

McLeod, E., Salm, R.V., Green, A., Almany, J., 2008. Designing marine protected area networks to address the impacts of climate change. Front. Ecol. Environ. 7, 362370.

Mora, C., Sale, P., 2011. Ongoing global biodiversity loss and the need to move beyond protected areas: a review of the technical and practical shortcoming of protected areas on land and sea. Mar. Ecol. Prog. Ser. 434, 251-266.

Munawar, M., Price, A.R.G., Munwar, I.F., Carou, S., Niblock, H., Lorimer, J., 2002. Aquatic ecosystem health of the Arabian Gulf: status and research needs. In Khan, N.Y., Munwar, M., Price, A.R.G. (Eds.), The Gulf Ecosystem Health and Sustainability. Backhuys Publishers, Leiden, pp. 303-326.

Murray, S.N., Ambrose, R.F., Bohnsack, J.A., Botsford, L.W., Carr, M.H., Davis, G.E Dayton, P.K., Gotshall, D., Gunderson, D.R., Hixon, M.A., Lubchenco, J., Mangel M., MacCall, A., McArdle, D.A., Ogden, J.C., Roughgarden, J., Starr, R.M., Tegner, M.J., Yoklavich, M.M., 1999. No-take reserve networks: sustaining fishery populations and marine ecosystems. Fisheries 24, 11-25.

Pauly, D., Christensen, V., Guenette, S., Pitcher, T.J., Sumaila, U.R., Walters, C.J., Watson, R., Zeller, D., 2002. Towards sustainability in world fisheries. Nature 418, 689-695.

Price, A.R.G., Sheppard, C.R.C., Roberts, C.M., 1993. The Gulf: its biological setting. In: Price, A.R.G., Robinson, J.H. (Eds.), The 1991 Gulf War: Coastal and Marine Environmental Consequences. Mar. Poll. Bull., vol. 27, pp. 9-15.

Riegl, B., 1998. A new reef marine reserve in the southern Arabian Gulf - Jebel Ali (Dubai, United Arab Emirates). Coral Reefs 17, 398.

Riegl, B., Purkis, S.J., Kohle, K., Dodge, R.E., 2006. Spatial patterns in Arabian Gulf coral assemblages (Jebel Ali, Dubai, U.A.E.) in response to temperature forcing. In: Proceedings of the 10th International Coral Reef Symposium, Okinawa, pp. 683-687.

Riegl, B.M., Purkis, S.J., Al-Cibahy, A.S., Al-Harthi, S., Grandcourt, E., Al-Sulaiti, K. Baldwin, J., Abdel-Moati, A.M., 2012. Coral bleaching and mortality thresholds in the SE Gulf: highest in the world. Coral Reefs World 3, 95-105.

Rivero Blanco, C., Gabaldon, M., 1992. The evaluation of natural protected area systems: a numeric method. Parks 3, 11-13.

Roberts, C.M., Branch, G., Bustamante, R.H., 2003a. Application of ecological criteria in selecting marine reserves and developing reserve networks. Ecol. Appl. 13 215-228.

Roberts, C.M., Andelman, S., Branch, G., 2003b. Ecological criteria for evaluating candidate sites for marine reserves. Ecol. Appl. 13, 199-214.

Roberts, C.M., Hawkins, J.P., Gell, F.R., 2005. The role of marine reserves in achieving sustainable fisheries. Philos. Trans. Roy. Soc. B 360, 123-132.

Roff, J.C., 2005. Conservation of marine biodiversity: too much diversity, too little co-operation. Aquat. Conserv.: Mar. Freshw. Ecosyst. 15, 1-5.

Rogers, A.D., Laffoley, D.d'A., 2011. International Earth System Expert Workshop on Ocean Stresses and Impacts. Summary Report. IPSO Oxford, 18 pp.

Regional Organization for the Protection of the Marine Environment (ROPME) 2003. The State of the Marine Environment Report. ROPME/GC-11/003, Kuwait.

Sale, P.F., Feary, D.A., Burt, J.A., Bauman, A.G., Cavalcante, G.H., Drouillard, K.G. Kjerfve, B., Marquis, E., Trick, C.G., Usseglio, P., Van Lavieren, H., 2011. The growing need for sustainable ecological management of marine communities of the Persian Gulf. Ambio 40, 4-17.

Sheppard, C., Al-Husiani, M., Al-Jamali, F., Al-Yamani, F., Baldwin, R., Bishop, J. Benzoni, F., Dutrieux, E., Dulvy, N., Durvasula, S., Jones, D., Loughland, R., Medio D., Nithyanandan, M., Pilling, G., Polikarpov, I., Price, A., Purkis, S., Riegl, B., Saburova, M., Namin, K., Taylor, O., Wilson, S., Zainal, K., 2010. The Gulf: a young sea in decline. Mar. Pollut. Bull. 60, 13-38.

Spalding, M., Fish, L., Wood, L.J., 2008. Towards representative protection of the world's coasts and oceans - progress, gaps, and opportunities. Conserv. Lett. 1, 217-226.

Spalding, M., Wood, L., Fitzgerald, C., Gkerde, K., 2010. The 10\% target: where do we stand? In: Toropova, C., Meliane, I., Laffoley, D., Matthews, E., Spalding, M. (Eds.), Global Ocean Protection: Present Status and Future Possibilities. Brest, 
ARTICLE IN PRESS

H. Van Lavieren, R. Klaus/Marine Pollution Bulletin $x x x$ (2012) $x x x-x x x$

17

France. Agence dee aires marines protégées, Gland, Switzerland, Washington, DC and New York, USA: IUCN WCPA, Cambridge, UK: UNEP-WCMC, Arlington, USA: TNC, Tokyo, Japan: UNU, New York, USA: WCS, 96 pp.

Staub, F., Hatziolos, M.E., 2004. Score Card to Assess Progress in Achieving Management Effectiveness Goals for Marine Protected Areas. World Bank, 30 pp.

Stolton, S., Dudley, N., Hockings, M., MacKinnon, K., Whitten, A., 2003. Reporting Progress at Protected Area Sites, World Bank and WWF, 15 pp.

Stolton, S., Hockings, M., Dudley, N., MacKinnon, K., Whitten, T., Leverington, F., 2007. Reporting Progress in Protected Areas: A Site-level Management Effectiveness Tracking Tool, second ed. World Bank/WWF Forest Alliance, Gland, Switzerland.

Tayefeh, H.F., Zakaria, M., Amini, H., Ghasemi, S., Meysam, G., 2011. Breeding waterbird populations of the islands of the northern Persian Gulf: Iran. Podoces $6,49-58$.

United Nations Department of Economic and Social Affairs (UN DESA), 2010. World Population Prospects, the 2010 Revision. <www.unpopulation.org>.

United Nations Environment Programme (UNEP), 1999. Overview on Land-based Sources and Activities Affecting the Marine Environment in the ROPME Sea area. UNEP Regional Seas and Reports and Studies, No. 169.

United Nation Environment Programme World Conservation Monitoring Center (UNEP-WCMC), 2008. National and Regional Networks of Marine Protected Areas: A Review of Progress. UNEP-WCMC, Cambridge.

Van Lavieren, H., Burt, J., Feary, D.A., Cavalcante,G., Marquis, E., Benedetti, L., Trick, C., Kjerfve, B., Sale, P.F., 2011. Managing the Growing Impacts of Development on Fragile Coastal and Marine Ecosystems: Lessons from the Gulf. A Policy Report, UNU-INWEH: Hamilton, Canada.

Wilkinson, C., 2008. Status of Coral Reefs of the World. Australian Institute of Marine Science, Townsville.

Wilson, S., Fatemi, S. M. R., Shokri, M. R., Claereboudt, M., 2002. Status of Coral Reefs of the Persian/Arabian Gulf and Arabian Sea Region. In: Wilkinson, C.R. (Ed.), Status of Coral Reefs of the World. GCRMN Report, Australian Institute of Marine Science, Townsville, pp. 53-62.

Wood, L.J., 2007. MPA Global: A Database of the World's Marine Protected Areas. Sea around Us Project, UNEP-WCMC and WWF. <http://www.mpaglobal.org>. Wood, L., Fish, L., Laughgren, J., Pauly, D., 2008. Assessing progress towards global marine protection targets: shortfalls in information and action. Oryx 42, 340351.

World Bank, 2012. World Bank Indicators Database. <http://data.worldbank.org/ indicator/> (accessed 10.08.12).

World Resources Institute (WRI), 2008. Persian Gulf: The Cost of Coastal Developments to Reefs. <http://www.wri.org/publication/reefs-at-riskrevisited/stories/persian-gulf $>$.

World Summit on Sustainable Development (WSSD), 2002. Report of the World Summit on Sustainable Development, A/CONF.199/20. Johannesburg, South Africa.

World Wildlife Fund (WWF), 2008. Conservation and Management Plan for Abu Dhobi and Eastern Qatar Coral Reefs. <http://assets.panda.org/downloads/ coral_reef_management_plan.pdf>.

Please cite this article in press as: Van Lavieren, H., Klaus, R. An effective regional Marine Protected Area network for the ROPME Sea Area: Unrealistic

vision or realistic possibility?. Mar. Pollute. Bull. (2012), http://dx.doi.org/10.1016/j.marpolbul.2012.09.004 